\title{
Temporal variations of volume transport through the Taiwan Strait, as identified by three-year measurements
}

\author{
Hsien-Wen Chen ${ }^{\mathrm{a}}$, Cho-Teng Liu ${ }^{\mathrm{b}}$, Takeshi Matsuno ${ }^{\mathrm{c}}$, Kaoru Ichikawa ${ }^{\mathrm{d}}$, \\ Ken-ichi Fukudome ${ }^{\mathrm{e}}$, Yih Yang ${ }^{\mathrm{f}}$, Dong-Jiing Doong ${ }^{\mathrm{g}}$, and Wei-Ling Tsai ${ }^{\mathrm{f}}$
}

${ }^{a}$ Department of Maritime Police, Central Police University, Taiwan, ROC.

No.56, Shujen Rd., Takang Village, Kueishan District, Taoyuan, 33304, Taiwan, R.O.C.

e-mail: hsienwenchen@gmail.com

${ }^{\mathrm{b}}$ Institute of Oceanography, National Taiwan University, Taiwan, R.O.C.

No. 1, Sec. 4, Roosevelt Road, Taipei, 10617, Taiwan, R.O.C.

e-mail: ctliu@ntu.edu.tw

${ }^{c}$ Research Institute of Applied Mechanics, Kyushu University, Japan

6-1 Kasugakohen, Kasuga, Fukuoka, 816-8580, Japan

e-mail: matsuno@ riam.kyushu-u.ac.jp

${ }^{\mathrm{d}}$ Research Institute of Applied Mechanics, Kyushu University, Japan

6-1 Kasugakohen, Kasuga, Fukuoka, 816-8580, Japan

e-mail: kaochin69@gmail.com

${ }^{\mathrm{e}}$ Physical Oceanography Group, Fisheries Oceanography Division, Japan Sea National Fisheries Research Institute, Japan.

1-5939-22, Suido-cho, Chuou-ku, Niigata-shi, Niigata, 951-8121, Japan

e-mail: dome@affrc.go.jp

f Taiwan Ocean Research Institute, National Applied Research Laboratories, Taiwan, R.O.C. No.219, Sec.1, Dongfang Rd., Qieding Dist., Kaohsiung City 852, Taiwan, R.O.C. e-mail: yy@narlabs.org.tw

${ }^{\mathrm{g}}$ Department of Hydraulic and Ocean Engineering, National Cheng Kung University, Taiwan, R.O.C. 1, University Road, Tainan 70101, Taiwan, R.O.C. 
e-mail: doong@mail.ncku.edu.tw

Corresponding author: Cho-Teng Liu, Institute of Oceanography, National Taiwan University, No. 1, Sec. 4, Roosevelt Road, Taipei, 10617, Taiwan, R.O.C.

Phone: +886-915-003-185, e-mail: ctliu@ntu.edu.tw 
Abstract. The water characteristics of the East China Sea depend on influxes from river run-off, the Kuroshio, and the Taiwan Strait. A three-year observation using an acoustic Doppler current profiler (ADCP) operated on a ferry provides the first nearly continuous data set concerning the seasonal flow pattern and the volume transport from the Taiwan Strait to the East China Sea. The observed volume transport shows strong seasonality and linkage to the along-strait wind stress. An empirical regression formula between the volume transport and wind was derived to fill the gaps of observation so as to obtain a continuous data set. Based on this unique data set, the three-year mean of monthly volume transport is northeastward throughout the year, large (nearly $3 \mathrm{~Sv}$ ) in summer and low (nearly zero) in winter. The China Coastal Current flows southward in winter, while the northward-flowing Taiwan Strait Current may reverse direction during severe northeasterly winds in the winter or under typhoons. The sea level difference across Taiwan Strait is closely correlated to the transport through the strait, and their relation is found seasonally nearly stable.

Keywords: volume transport, Taiwan Strait, wind stress, sea level difference 


\section{Introduction}

The East China Sea (ECS) is located at the western edge of the Pacific Ocean and is well-known as a marginal sea with important biological resources. Circulation in the shelf region of the ECS has been of interest to many researchers because various factors, such as the Kuroshio intrusion, Taiwan Warm Current, Changjiang discharge, tidal motions, and wind effects, contribute to its current system. The Taiwan Warm Current plays an especially important role in the circulation throughout the ECS (Fang et al., 1991). The major source of the Taiwan Warm Current is the water mass passing through the Taiwan Strait (TwS), the so-called Taiwan Strait Current. Therefore, understanding the behavior of the Taiwan Strait Current is important to understanding the shelf circulation of ECS.

Many reports have presented current observations in the TwS, but most were based on indirect measurements and measurements that were randomly distributed in space and time or consisted of a series of short-term measurements. Based on the observations of ship drifts, Wyrtki (1961) shows that the mean current in TwS is NE in April, June, and August and SW in February, October, and December. Because ship drift is a combination of the ship velocity and the wind drag and current drag on the ship, and the wind drag on the ship is unlikely to be estimated accurately, the accuracy of such surface current velocity decreases with the wind speed, which is higher during the NE monsoon that spans from fall to spring. The SW monsoon spans from late spring to early fall. Here spring season is defined as March to May. Summer, fall and winter seasons start from June, September, and December, respectively.

Measurements using moored arrays give the most accurate current velocity and are more desirable in the winter, when all other methods of observation fail. However, moored instruments suffer from fishing activities, such that the longest observation is 2.5 months in the fall season (Teague et al., 2003; Lin et al., 2005) in the three-year field surveys. The data show that the current in TwS is mostly NE, except during events of strong northeasterly wind. Model studies by Wu and Hsin (2005) and Jan et al. (2002) were based on this set of data. Ko et al. (2003) used model simulation to explain the reversal of current in TwS as the result of Kelvin wave propagation from ECS to TwS during strong northeasterly events. 
Using shipboard acoustic Doppler current profiler (ADCP) surveys in 1999-2001, Wang et al. (2003) concluded that the annual mean volume transport $Q$ through TwS is $1.8 \mathrm{~Sv}\left(10^{6} \mathrm{~m}^{3} / \mathrm{s}\right)$, being $0.9 \mathrm{~Sv}$ in winter and 2.7 Sv in summer. Isobe (2008) summarized many snapshots and short-term observations by Zhao and Fang (1991), Liu et al. (2000), Wang et al. (2003), and Jan et al. (2006) and proposed an approximation of $Q$ through TwS: $Q=1.2+1.3 \cos (2 \pi(J u l i a n$ Day - 157)/365.2422). Hu et al. (2010) also reviewed various studies and concluded that $Q$ is "approximately $2.3 \mathrm{~Sv}$ northward in summer but approximately $0.8 \mathrm{~Sv}$ northward in winter". These numbers are higher than those of Isobe (2008): $1.2 \mathrm{~Sv}$ as the yearly mean, $0.29 \mathrm{~Sv}$ in winter, and $2.1 \mathrm{~Sv}$ in summer. A long-term observation is necessary to explain not only the difference in various reports, but also the characteristics of $Q$ 's variations of various time scales.

Ferry-mounted ADCP observations have been successfully applied to monitor the daily volume transport from ECS to the Sea of Japan through the Tsushima Strait (Takikawa and Yoon, 2005) and to resolve the tidal currents in the Marsdiep inlet of the Netherlands (Buijsman and Ridderinkhof, 2007). In the TwS, an ADCP was installed at the bottom of the Taima Ferry to survey the current beginning in January 2009. The Taima Ferry runs clockwise from Keelung $\left(25^{\circ} 08^{\prime} \mathrm{N}, 121^{\circ} 44^{\prime} \mathrm{E}\right)$ at 22:00 local time to

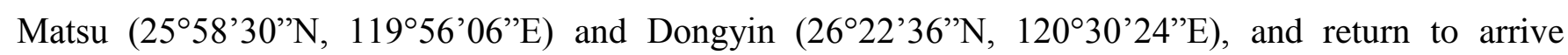
Keelung (Fig. 1) around 18:00 the next day. She runs counterclockwise the next day, and operates six times a week. Taima Ferry provides a unique platform for near-continuous measurements of currents in the northern end of TwS. The principal objectives of this implementation are to observe the total volume transport $(Q)$ through TwS (between ECS and SCS) and determine the seasonality of volume transport entering ECS from TwS.

This article is organized as follows. Section 2 introduces the method for acquiring the data used in this study. The results and analysis are presented in Section 3. Section 4 to 6 discusses the relationship between the volume transport and the wind, the response of the volume transport and the sea level difference to the wind, and the China Coastal Current. The conclusions of this study are presented in Section 7.

\section{Data Acquisition}




\subsection{ADCP Survey from Ferry Boat}

The Taima Ferry is $102.7 \mathrm{~m}$ long with a draft of $4.5 \mathrm{~m}$ and 5,039 gross tonnage. An RDI $300-\mathrm{kHz}$ Mariner ADCP was installed at the bottom of the ferry in December 2008. The sampling is averaged every minute over 4-m-depth bins starting at $8.2 \mathrm{~m}$ below the sea surface. The ship's heading, roll, and pitch data were recorded, and the bottom-tracking mode was selected to log the ship velocity. The crew of the Taima Ferry initiated the ADCP at the beginning of every cruise to collect ocean current profile data between Matsu and Keelung, that is, across the northern entrance of TwS (Fig. 1). After deducting approximately 60 days for annual maintenance work, one day off per week, days of no service due to severe weather events, and days with system failure, approximately 180 days of good ("percent good" $>80 \%$ ) profiles remained every year.

The ADCP measures current from a depth of $4 \mathrm{~m}$ below the sensor at the depth of $4.2 \mathrm{~m}$, to $94 \%$ of the distance from the ship bottom to the sea bottom, across TwS. These ADCP data permit the estimation of $Q$ through TwS. This estimation is based on ADCP data, and is named $Q_{a d c p}$. Low-quality ADCP data and unreasonable data were rejected, filled in by interpolation and then smoothed in the along-track direction to 0.01 longitudinal bins. Other than rough sea condition, the error of this bin-averaged velocity is a few $\mathrm{mm} / \mathrm{s}$ (Appendix). The surface layer velocity was extrapolated with the velocity of the first bin (at $8 \mathrm{~m}$ to $12 \mathrm{~m}$ below sea surface), and the bottom velocity was filled in with the velocity of the deepest bin. The error of this extrapolation increases with the wind speed, because the thickness and the Ekman velocity of surface Ekman layer increases with the wind stress, and this Ekman velocity enters the computation of $Q_{a d c p}$ as a source of error. Fig. 10 of Lin et al. (2005) shows that the vertical gradient of the mean current is small near the bottom boundary layer, and is not negligible near the sea surface.

The velocity shears in the top and bottom boundary layers are associated with the wind stress and the bottom frictional stress, respectively. These two Ekman transports result in errors in the estimation of along-strait transport $Q_{a d c p}$, and the error increases with the wind speed. However, since both of these stresses are mostly in the along-strait direction, resulting in the cross-strait transports, their errors would not be large in $Q_{a d c p}$. 


\subsection{Removing Tidal Current from ADCP-Measured Velocity Data}

Because the current in TwS is mostly driven by tides (Wang et al., 2003) and the M2 tide in the western North Pacific is strongest in ECS (Niwa and Hibiya, 2004), it is necessary to remove the tidal contribution from the observed current velocity before computing $Q$. There are three main approaches to detide the ship-mounted ADCP measurements. First, a least-squares fitting to the measured currents based on a set of pre-specified spatiotemporal functions has been widely used (Candela et al., 1992; Münchow, 2000; Wang et al., 2003). For sparse observations sampled with intervals longer than the tidal periods such as the daily ferry observations, this method solves the aliased tidal signals, so that it requires a long time series even if the noise amplitude is much smaller with respect to the signals. Wang et al. (2003) applied a set of Gaussian functions to the ADCP measurements near the northern entrance of TwS to derive the semi-diurnal tide, but they could not separate the two dominant tidal constituents, S2 and M2 tides. Furthermore, our time-fixed ferry data have nearly fixed phase vs. S2 tidal current, therefore it cannot derive S2 tidal component accurately near Taiwan (Appendix). Moreover, as noted by Erofeeva et al. (2005), this purely empirical method ignores the physics of tidal currents, resulting in tidal velocity and height fields that may not be dynamically or kinematically self-consistent. The second approach is to design a sampling strategy involving measuring currents at the same location several times in a tidal cycle to (a) average out the tide (Katoh et al., 1996; Jan and Chao, 2003) or (b) construct time series of currents at the chosen locations so that a harmonic analysis can be performed on the near-hourly data (Geyer and Signell, 1990) to derive tidal components. This method is not applicable to our data because the ferryboat can sample twice daily at the best condition, the three-year measurements have some missing data, and the harmonic analysis does not give accurate results particularly for S2 and K1 constituents because ferry departure time is at nearly fixed phase of S2 and K1 tides. As a result, we adopt the third approach, which is to make use of a numerical model to derive the tidal currents in the region of study. This method has been successfully applied by Foreman and Freeland (1991) and Carrillo et al. (2008).

The numerical model that we employed to remove the tidal current from the ADCP-measured velocity is the TPXO tidal model developed by Egbert et al. (1994) and Egbert and Erofeeva (2002). This model is barotropic with 2'×2' resolution in the China Seas region (http://volkov.oce.orst.edu/tides/YS.html). Its effectiveness in simulating the tidal current in TwS was validated by comparing the TPXO model results 
against the bottom-mount ADCP data reported by Lin et al. (2005). They reported that the M2 tide dominates over all other components by a factor of 2.5 or greater, vs. 3.5 or greater for the barotropic tidal constituent at $\left(121^{\circ} \mathrm{E}, 26^{\circ} \mathrm{N}\right)$ by TPXO. Ray (2001) found that the tidal current estimates from various tidal models agree with each other better than with the nearby mooring data. It may be interpreted as that mooring data contains high spatial frequency signal that have been smoothed out in the tidal model and the ferry ADCP data. The tidal current components can be derived accurately from the 3-year ferry data, except S2 component which synchronize with the ferry schedule. The ferry starts crossing TwS at the same phase of S2, everyday. We use the crossing time of the ferry at the middle of Keelung and Dongyin, to extract tidal current data from TPXO and to form a multi-year time series of tidal current. Then, the harmonic analysis was applied on this time series to recover the tidal components. The error in S2 and M2 components are about $5.8 \mathrm{~cm} / \mathrm{s}$ and $0.02 \mathrm{~cm} / \mathrm{s}$, respectively, for a 3-year long record. The error of $\mathrm{S} 2$ is unacceptable, therefore, TPXO is used to estimate the tidal current velocity in ADCP data.

An example of detided ADCP data, $\boldsymbol{U}_{\boldsymbol{r}}(x, y, z, t)$, for June 24, 2010 is depicted in Figs. 2a and 2b. The velocity structure shows low baroclinicity in both the along-strait component $U_{a}$ (positive at $35^{\circ}$ clockwise from true north) and the cross-strait component $U_{c}$, where the positives of $U_{a}$ and $U_{c}$ are northeastward and southeastward, respectively. Figs. $2 \mathrm{c}$ and $2 \mathrm{~d}$ show that the current on this day flows northeastward toward ECS both in the eastern part of TwS and along the China coast in the western third of TwS. Most of the transport through the strait is in the eastern half of $\mathrm{TwS}$, that is, east of $\left(120.5^{\circ} \mathrm{E}, 26^{\circ} \mathrm{N}\right)$, on that day. Because TPXO is a barotropic tidal model, there is no information on the vertical structure of the tidal current. Therefore, the uncertainty of the vertical structure of $\left(U_{a}, U_{c}\right)$ may increase with the stratification in the summer. Due to the lack of information on the baroclinicity of the tidal current, only the vertically averaged velocity and the volume transport are presented in the following sections of this article.

From $\boldsymbol{U}_{\boldsymbol{r}}$, one may derive the vertically averaged velocity along the ship's track across TwS and its horizontal integration, $Q$. Since $Q$ has been suggested to have a close relationship to the local wind, we jointly analyzed the hourly wind data from a nearby weather station of the Central Weather Bureau in Taiwan, Pengjiayu station $\left(122^{\circ} 4.28^{\prime} \mathrm{E}, 25^{\circ} 37.77^{\prime} \mathrm{N}\right.$, as shown in Fig. 1), to study the impact of variable wind on $Q$. The wind velocity $\boldsymbol{W}$ and wind stress $\boldsymbol{T}$ are decomposed into $\boldsymbol{W}=\left(W_{c}, W_{a}\right), \boldsymbol{T}=\left(T_{c}, T_{a}\right)$ $=\rho_{a} C_{d} \boldsymbol{W}|\boldsymbol{W}|$, where the subscripts $c$ and $a$ represent the cross-strait and along-strait directions, respectively. 
$\rho_{a}$ and $C_{d}$ are air density and drag coefficient of the wind on sea surface, assuming $\rho_{a} C_{d}=$ $0.00129 \times(0.06+0.71|\boldsymbol{W}|) \mathrm{kg} / \mathrm{m}^{3}$.

\section{Results and Analysis}

\subsection{Vertically Averaged Velocity along Ship Track}

The vertical averaged current velocity (Fig. 3) is maximum in the eastern third of the cross-strait track, and its magnitude exceeds $0.3 \mathrm{~m} / \mathrm{s}$ throughout a year with the exception of a few days. In summer, the bi-monthly mean maximum velocity is approximately $0.5 \mathrm{~m} / \mathrm{s}$ and gradually decreases toward both the China and Taiwan coasts monotonically, while the magnitude of the current velocity is minimal in winter with a somewhat undulated distribution from autumn to winter. Although the inter-annual variation of the current field seems to be small in summer, year-to-year variations in the current field are observed from autumn to winter.

In many cases, $\boldsymbol{U}_{\boldsymbol{r}}$ shows variations on all daily, weekly and seasonal time scales. The seasonal variation of the velocity structure in TwS is most apparent in the China Coastal Current (CCC) which may switch to SW direction (Fig. 3) during severe NE monsoon.

The three-year (2009-2011) mean of these bimonthly mean velocity structures is presented in Fig. 4a for the cross-strait sections of the along-strait velocity $U_{a}$ and in Fig. $4 \mathrm{~b}$ for the vertically averaged mean of $\boldsymbol{U}_{r}$. The number of cruises is listed in Table 1. There are two ADCP sections each day. These results show year-long NE flow toward ECS, except near the coast of China in winter.

Both Fig. 3 and Fig. 4 give a general picture of the seasonality of the depth-averaged velocity across TwS and interannual variability from 2009 and 2011. As reported in previous studies, the mean current is northeastward, stronger and stable during summer, and weaker and variable during winter. Larger transport is found in the eastern two-thirds of TwS where $U_{a}$ is larger and the water is deeper, as shown in Fig. 4a.

Near the China coast, the mean current is southwestward from September until the following April. 
Oceanic fronts often occur at places with opposing currents or large velocity shear. The oceanic front in the northern TwS is the transition zone between the southward-flowing CCC and the NE current along the axis of TwS. The change in sign of $U_{a}$ in the western half of TwS (Figs. 3 and 4) means that colder surface water from the north is limited in the western half of TwS and that its interface with the current from the warmer south is likely to form a frontal region of sea surface temperature (Lee et al., 2014). This is consistent with the sea surface temperature front (Chen, 2003; Zhu et al., 2004). The sea surface temperature front is limited in the western quarter to third of TwS. Lin et al. (2005) found that the southward CCC is mostly present in the western part of TwS (similar to the Sept-Feb plots in Fig. 4a) and across the whole TwS only during severe northeasterly events. The CCC will be further discussed in Section 6.

\subsection{Volume Transport from the Taiwan Strait to the East China Sea}

Let $d s$ be a small segment along the cruise line and $V_{n}$ be the cross-track component of $\boldsymbol{U}_{r} . V_{n}$ is normal to $d s$ and is in the direction toward ECS. In this case, $V_{n}=u_{r} \times \sin (\alpha)+v_{r} \times \cos (\alpha)$, where $\alpha$ is the angle clockwise from the east to $d s$ at a given point along the ship track (SE-NW or NE-SW) and $u_{r}$ and $v_{r}$ are the eastward and northward components of $\boldsymbol{U}_{\boldsymbol{r}}$, respectively. The through-strait volume transport $Q$ towards ECS is defined as the integration of $V_{n}$ over the water column $(-h(s)<z<0)$ across TwS along a ship track $s$ with $0<s<L$ :

$$
Q_{a d c p}=\int_{0}^{L} \int_{-h(s)}^{0} V_{n}(s, z) \cdot d z \cdot d s
$$

For the westbound leg, $s=0$ is at Keelung and $s=L$ is at Matsu. For the eastbound leg, they are reversed. The daily value of $Q_{a d c p}(\mathrm{~Sv})$ is the average over a given day, and $Q_{a d c p}$ hereafter is the daily mean volume transport. The observed $Q_{a d c p}$ in 2009, 2010, and 2011 are shown in Fig. 5. Both the data density and the value of $Q_{a d c p}$ are high in the summer and low in the winter, except in August and September 2011, during which data were not obtained due to a system malfunction. 


\section{Volume Transport and Local Wind}

It should be noticed, however, that the number of available data also shows a strong seasonality and interannual change (Table 1). Since the ferry service was minimal in January (i.e. before the Chinese New Year) mainly due to severe sea state, the mean transport with the observed transport data $Q_{a d c p}$ alone may miss the lower value of $Q$ during severe sea states under northeasterly monsoon. In order to estimate the unbiased temporal mean $Q$, the missing $Q_{a d c p}$ on days of severe weather (e.g. typhoons and winter monsoons) should be filled before deriving the temporal average of $Q$. Because the sampling bias is caused by the wind stress $T$, regression analysis is performed on $Q$ and $T$ in this section to fill the gaps in the observed $Q_{a d c p}$.

\subsection{Wind Stress at Pengjiayu}

First, we would evaluate how strongly $Q_{a d c p}$ correlates with the wind stress. In general, it would be best to compare $Q_{a d c p}$ with the wind field over the whole TwS close in time, which is obtained from the satellite or from several weathers station less influenced by the land. However, the satellite wind data over the sea surface are not uniform in time, and no proper island stations are available within TwS. During the northeasterly season, the Pengjiayu weather station is located at the upwind side and in the ECS; therefore, its hourly wind measurements do not suffer from substantial influence from large land masses. Fig. 6a shows the 40-h low-passed Pengjiayu wind velocity vectors of 2009-2011, and Fig. 6b shows the scatter plot of the daily values of along-strait wind from Pengiiayu (abscissa) versus those from the analysis of satellite scatterometer wind data at $\left(121.2^{\circ} \mathrm{E}, 25.8^{\circ} \mathrm{N}\right)$ near the Taima cruise lines. The satellite wind data were retrieved from the Asia Pacific Data Research Center (APDRC) at the website http://apdrc.soest.hawaii.edu/data/data.php. The satellite-derived surface wind velocity along TwS is 1.01 times that of the Pengjiayu wind, with a bias of $-2.4 \mathrm{~m} / \mathrm{s}$ and a correlation coefficient of 0.823 (Fig. $6 \mathrm{~b}$ ); the correlation is better during the winter northeasterly monsoon than during the summer southwesterly, when Pengjiayu island is on the lee side of Taiwan island. Based on this similarities, the wind data from the Pengjiayu weather station are further used in this study to obtain benefits of temporally dense hourly observations. 
The northeasterly starts around mid-September (Fig. 6a) and continues until mid-April, and the southerly wind lasts from mid-June to early September. These timings are similar to that of the change in $Q$, which is high from June to August (Fig. 5). Evident seasonality can be found in all Figs 3 - 5, i.e., larger northward flow under southwesterly winds during summer monsoon, and smaller transport under northeasterly winds during winter monsoon. The present data set permits a more detailed study of the monthly variability of the volume transport and its relation to the wind stress, than the traditional cosine fit of $Q$ by Isobe (2008).

\subsection{Correlation and Lag between Volume Transport and the wind stress}

The along-strait wind stress $T_{a}$ is cross-correlated with $Q_{a d c p}$ (both are positive in the northeastward direction) which is the average of westbound and eastbound leg of her cruise. The average time of these two ADCP measurements at each longitude is needed to represent the time of $Q_{\text {adcp. The Taima Ferry sails }}$ westward from Keelung Harbor at 22:00 local time or earlier and returns from Matsu at 09:30 the next morning. Arrival and departure time at Dongyin depends on the cruise is clockwise or counter clockwise. Taima Ferry crosses $121.6^{\circ} \mathrm{E}$ at approximately 23:31 on the westbound leg and 16:59 on the eastbound leg, and the mean crossing time is $08: 15$. For crossing $121^{\circ} \mathrm{E}$, the times are $02: 18,14: 31$, and $08: 24$ respectively. Because the arrival time at Matsu is about 07:00, and the departure time is 09:30, the mean time off Matsu is 08:15. So, 08:20 is a reasonable estimate of crossing time at all locations along the ferry line and 08:20 is taken as the mean measurement time of $Q_{a d c p}$ by Taima Ferry. Fig. 7 depicts the correlation between $Q_{a d c p}$ and the daily mean $T_{a}$ for various along-strait wind directions and the lag-hours of $T_{a}$ after $Q_{a d c p}$. It shows that the daily mean $T_{a}$ leads $Q_{a d c p}$ by 5 to $10 \mathrm{~h}$ (or an average of approximately 7.5 h) for the correlation coefficient $\gamma=0.75$ contour and the along-strait direction of the wind stress is $25-50^{\circ}$. In the following analysis, the daily $T_{a}$ is defined as the 23-hour mean $T_{a}$ centered at 01:00 Taipei time and pointing $35^{\circ}$ clockwise from North.

\subsection{Wind-Induced Volume Transport}


The regression relation between the daily mean transport $Q_{a d c p}$ and the daily mean $T_{a}$ yields a correlation coefficient $\gamma\left(Q_{a d c p}, T_{a}\right)=0.757$, with bias 2.00 and slope 16.03 . Therefore, transport may be estimated as $Q_{e}$ from $T_{a}$ centered at 01:00 Taipei time:

$$
Q_{e}=2.00+16.03 T_{a}, \quad \gamma=0.757
$$

Meanwhile, , regression analysis on the cross-strait wind stress $T_{c}$ and $Q_{a d c p}$ shows that $Q=1.7$ $3.46 T_{c}$ with correlation coefficient $\gamma=-0.162$. Since $T_{c}$ is less correlated with $Q_{a d c p}$ than does $T_{a}$, this study henceforth restricts itself to considering only $T_{a}$.

The scatterplot of $T_{a}$ and $Q_{a d c p}$ in Fig. 8a demonstrates that $T_{a}$ and $Q_{e}$ are well correlated to each other, especially in the range of wind stress of -0.2 to $0.2 \mathrm{~Pa}$; the root mean square difference $0.64 \mathrm{~Sv}$. Note that this estimate may be less reliable under extraordinary wind conditions because no $Q_{a d c p}$ data were collected in such days and extrapolation by the linear regression for extraordinary Ta may not be applicable if non linearity is too large. Teague et al. (2003) presented plots of transports from current meter mooring data and $T_{a}$ near TwS, which show that one event of peak southward transport of approximately $5 \mathrm{~Sv}$ was associated with maximal northeasterly wind stress about -0.6 Pa. The estimate in Eq. (2) becomes -7.6 Sv, resulting in $2.6 \mathrm{~Sv}$ overestimation out of the $7 \mathrm{~Sv}$ wind-induced transport depression. However, Figs $6 \mathrm{a}$ and $8 \mathrm{~b}$ show that such one-day events with extraordinary spikes of $T_{a}$ or $\mathrm{Q}$ (say, deviation larger than $0.2 \mathrm{~Pa}$ ) occur only about 10 days per year.

The regression relations Eq. (2) suggests that $Q_{e}$ may be separated into two parts: one related to the large-scale, longer-term (or nearly constant for several days) subtropical ocean circulation (Kuroshio and northern SCS) $Q_{o}$, which is represented as the constant term $2.00 \mathrm{~Sv}$ in Eq. (2), and the other related to the along strait wind stress $T_{a}$

$$
Q_{w}=16.03 T_{a} .
$$

$Q_{o}$ is the volume transport of TwS that is related to the much larger spatial scale and longer temporal scale than the local seasonal wind and hence decreases the correlation between $Q_{a d c p}$ and $T_{a}$. Such wind-free transport may be the result of the pressure gradient flow from the North Pacific general circulation and the frictional drag from the sea bottom east of Taiwan on Kuroshio (Yang, 2007); Yang (2007) suggested that 
the mean flow in TwS is caused by this island friction on Kuroshio.

After the gaps of $Q_{a d c p}$ are filled with $Q_{e}$, a new time series of volume transport $Q_{f}$ is formed. The monthly mean of $Q_{f}$ should have less bias and therefore better accuracy for estimates of the temporal mean. Table 2 lists the monthly mean observed $Q$ and $Q_{f}$, which equals the observed $Q_{a d c p}$ plus the gaps of $Q_{a d c p}$ filled by $Q_{e}$, as shown in Fig. 8b. It is apparent that there were no observations at large spikes of $Q_{f}$, especially during typhoon passings (the largest two typhoons in 2009 are Moraku during August 6 to 10, and Parma during October 4 to 5, http://rdc28.cwb.gov.tw/TDB/ntdb/pageControl/typhoon) and in the fall and winter seasons. This is due to the lack of ferry service on days of severe sea states, that is, on days of low $Q_{f}$ values or even negative $Q_{f}$ values. $Q_{f}$ is therefore provides better temporal mean of volume transport through TwS. Fig. 9a plots $Q_{f}$ with a seven-day running mean and the annual mean of $Q_{f}$.

The cosine fit of $Q_{t}$ in Fig. $9 \mathrm{~b}$ is

$$
Q_{t}=1.32+1.07 \cos (2 \pi(\text { Julian Day }-169.1) / 365.2422)
$$

In comparison to the equation suggested by Isobe (2008), $Q_{i}=1.2+1.3 \cos (2 \pi$ (Julian Day -157$) /$ 365.2422), $Q_{t}$ from Eq. (4) has an approximately $10 \%$ higher mean, approximately $20 \%$ less oscillation, and peaks 12 days later. There is no overlap among the data in Isobe (2008) and the data in this study, but the approximation equations are similar to each other. Due to the much higher sampling rate, $Q_{f}$ gives more details on the monthly variation and the interannual variation. Note that typhoon events are more frequent in August near Taiwan, and the monsoonal wind frequently changes direction from mid-September to October, whose characteristics are reflected in the larger standard deviation of the monthly mean $Q_{f}$ in Fig. $9 b$.

\subsection{Including Local Wind Effects Improves Compatibility among Observed Transports}

Figs. 5 and 9a show that the daily, weekly, seasonal, and inter-annual variations of $Q$ are significant. Table 2 shows that $Q_{f}$ of 2011 increases from 1.05 Sv in March to $2.78 \mathrm{~Sv}$ in July, with a maximum exceeding $3 \mathrm{~Sv}$ for a few days in the spring and summer (Fig. 5). It remains above $2 \mathrm{~Sv}$ in the summer and 
then rapidly decreases to less than $1 \mathrm{~Sv}$ as the northeasterly winter monsoon picks up in late September (Fig. 6). The value of $Q$ in summer has relatively little variability, suggesting a stable current because of less intensive wind events, except for typhoons. On the other hand, $Q$ shows large variability from autumn to spring, with an annual average less than $2 \mathrm{~Sv}$. This strong dependence of $Q$ on $T_{a}$ in Eq. (2) may be used to explain the large differences among the observed volume transports summarized in Isobe (2008).

Liu et al. (2000) conducted their ADCP surveys on 1997/3/6 at opposite phases of the M2 tide, that is, $6.21 \mathrm{~h}$ apart, using two research vessels. Their $Q$ is far above Isobe's curve for $Q$ in March. Fig. 10 plots the wind velocity at Pengjiayu by the year and month of the cruise of Liu et al. (2000). Because it takes some time for the wind to drive ocean current, the averaged $W_{a}$ of 5-6 March 1997 at Pengjiayu weather station is $1.94 \mathrm{~m} / \mathrm{s}$, whereas the $1993-2001$ mean $W_{a}$ of March is $-2.02 \mathrm{~m} / \mathrm{s}$. From Eq. (2),

$$
Q(\text { daily })-Q(\text { monthly })=16.03 \times\left[T_{a}(\text { daily })-T_{a}(\text { monthly })\right]
$$

or,

$$
Q(\text { monthly })=Q(\text { daily })-16.03 \times\left[T_{a}(\text { daily })-T_{a}(\text { monthly })\right]
$$

The two-day mean wind stress of Liu et al. (2000) was $0.0164 \mathrm{~Pa}\left(T_{a}\right.$ (daily)), which is $0.0704 \mathrm{~Pa}$ above the $T_{a}$ (monthly) of $-0.054 \mathrm{~Pa}$. This difference means that the estimate of $Q$ (daily) $=2.6 \mathrm{~Sv}$ by Liu et al. (2000) is below the condition of abnormal wind stress relative to the average wind stress in March. To derive $Q$ (monthly) for March, $Q$ must be adjusted for the mean wind stress of March. That is, $Q$ (monthly) for March should be $16.03 \times 0.0704=1.13 \mathrm{~Sv}$ less than the estimate of $2.6 \mathrm{~Sv}$ by Liu et al. (2000), that is, $Q$ of March from their data should be $1.47 \mathrm{~Sv}$. This estimate of $Q$ falls right back to the cosine fit by Isobe (2008).

This estimate of the monthly mean $Q$ from the two-day ADCP survey may serve as indirect evidence of the dependence of $Q$ on $T_{a}$ in Eq. (2). It also means that deviation of various estimates of $Q$ from the monthly mean $Q$ in Isobe (2008) is likely due to the wind stress during their surveys deviating from the monthly mean wind stress. The major differences among various observations and model simulations may be greatly reduced by excluding the effect of anomalous wind stress during their surveys. Using the multiyear mean of $T_{a}$, one may extract the monthly mean transport through TwS from Fig. 11 . This result 
implies that the monthly mean volume transport in TwS is northward throughout the year. The ship drifts in TwS is SW under the northeasterly wind of the winter monsoon (Nitani, 1972), but Guan (1986) observed northward surface flow under northeasterly wind. Figs. 3 and 4 suggest that the CCC occurs only during winter; it is quite eventful (Lin et al., 2005), and its monthly average is much lower than the northward flow in the eastern three-quarters of TwS. Because of the large variability of $T_{a}$, the seven-day running mean of $Q$ often varies by more than $2 \mathrm{~Sv}$ (Fig. 9) and varies by over $3 \mathrm{~Sv}$ twice in 2011 (early February and early October, Fig. 9).

\section{Geostrophy, Volume Transport and Sea Level Differences}

Based on the principle of geostrophic balance, increasing $Q$ value would mean increasing along-strait surface current, which corresponds to an increase in the tilt of the sea surface, being higher at the Taiwan side. The relationship between the tilt of the sea surface and $Q$ depends on the contribution ratio of the surface current to the vertically averaged transport $Q$, so it may vary seasonally if the vertical structure of the current changes (Takikawa and Yoon, 2005). To study this relationship, the tidal data of Kinmen $\left(118.43^{\circ} \mathrm{E}, 24.4086^{\circ} \mathrm{N}\right)$ and of Mailiao $\left(120.1607^{\circ} \mathrm{E}, 23.7861^{\circ} \mathrm{N}\right)$, located on opposite sides of $\mathrm{TwS}$, are selected to compare with $Q_{a d c p}$. The tidal contribution was first removed (Pawlowicz et al., 2002) to find the detided sea level height (SLH) at Mailiao and Kinmen. The SLH contains both the unknown offset and sea level variations of all frequencies except tidal frequencies.

The sea level difference (SLD) across TwS is defined as the SLH at Mailiao minus SLH at Kinmen, which still includes the unknown offset. If the cross section of TwS is rectangular, the current is steady, frictionless, and barotropic, the geostrophic volume transport $Q_{g}$ may be estimated by $(g \cdot h / f) \cdot(\mathrm{SLD}-$ offset), where $f=$ the Coriolis parameter at $24^{\circ} \mathrm{N}, g=9.8 \mathrm{~m} / \mathrm{s}^{2}$, and $h \sim 50 \mathrm{~m}$ as the mean water depth between Kinmen and Mailiao, the slope $g \cdot h / f \sim 8.28 \mathrm{~Sv} \mathrm{~m}^{-1}$. It means that for $1 \mathrm{~m}$ increase of SLD, $Q_{g}$ increases by $8.28 \mathrm{~Sv}$.

The regression relation between $Q_{a d c p}$ and SLD (Fig. 12) shows that the slope is $6.07 \mathrm{~Sv} \mathrm{~m}^{-1}$ for the whole data, with a very high correlation coefficient 0.91 . Note that the long-term large-scale transport $Q_{0}$, 
which is independent of local winds, is expected to be in the geostrophic balance, so that the correlation between $Q$ and SLD would be eventually higher than that between $Q$ and $T_{a}$. This slope value is about $73 \%$ of the barotropic frictionless case calculated above. This would be consistent with vertically near-homogeneous velocity structures with frictional reductions near the bottom shown in Fig.4a.

Remarkably, the slopes of the regression lines in summer and winter show similar tendency; 6.14 in summer monsoon and 6.17 in winter monsoon. Considering that the correlation coefficients are still large ( 0.90 in summer and 0.89 in winter), the contribution ratio of the surface current to $Q$ is found seasonally stable in TwS, unlike in the Tsushima Strait (Takikawa and Yoon, 2005). It implicates that the wind-driven part of the current in TwS is mostly barotropic. As shown in Fig. 4a, the baroclinicity of current velocity is similar for all seasons and it results a relatively stable contribution ratio of SLD (or the geostrophic current) to the vertical integrated $Q$ for both summer and winter seasons.

\section{China Coastal Current}

When the northeasterly monsoon picks up, the southward CCC increases (Fig. 3) and the volume transport $Q$ decreases. CCC starts in September, becomes faster and wider from October to January and then dwindles in March and April.

Positive values of $Q$ indicate warmer water flowing northward through TwS, and vice versa. If the estimated $Q_{e}$ of Eq. (2) is reasonably accurate, $Q_{e}$ was negative from early January to early February in 2011 (Fig. 9), implying that the strong northeasterly wind in TwS strengthened the southward flow (the cold CCC) and weakened (or even reversed) the northward flow in the eastern part of TwS (Liao et al., 2013). Beginning in early February of 2011, the pen fishery in Penghu islands (in central TwS) suffered severe damage caused by abnormally cold water. The same damage also occurred in February 2008 (Lee et al., 2014). Comparing to the El Niño index, NINO3.4, both TwS and the eastern equatorial Pacific showed a severe decrease in sea surface temperature in early 2008 and early 2011, the La Niña years of anomalously low values of NINO3.4 relative to the period since 2001 (the full NINO3.4 series can be found at http://stateoftheocean.osmc.noaa.gov/sur/pac/nino34.php). The low temperature observed in TwS 
in early 2011 would be caused by strengthened southward flow shown in Fig. 9 (red dots in late January), which was generated by the enhanced northeasterly wind in the winter of La Niña years.

In the winter, TwS is mostly cloudy, and satellites can seldom image the ocean. However, a monthly composite of satellite images could provide a rough picture of water masses. The moderate-resolution imaging spectroradiometer (MODIS) onboard satellites Terra and Aqua may provide information on the particulate inorganic carbon (PIC, essentially the calcium carbonate of coccolithophore) (Acker and Leptoukh, 2007). Fig. 13 shows the monthly average PIC in TwS for February 2010. The open ocean water (low PIC) occupies the central part of TwS, and the southward-flowing CCC (Fig. 3), which contains a high concentration of PIC from the coast or from ECS, is confined relatively close to the China coast.

\section{Conclusions}

The data set utilized in this study is unique in that it is the only set of long-term ocean current measurements to assess the volume transport from the SCS to the ECS. The monthly mean of observed volume transport through TwS varies from 0.4 to $2.8 \mathrm{~Sv}$, excluding days of severe weather. The substantial correlation between volume transport and the wind stress permits an estimate of volume transport in days without data, $Q_{e}=2+16.03 T_{a}$, resulting in the best time series of daily volume transport $Q_{f}$ which is high and stable during summer (June to August, average 2.37 Sv), and low from autumn to winter and spring (averages $0.72,0.64$, and $1.54 \mathrm{~Sv}$, respectively). The relation between volume transport and wind obtained here also help to clarify the different estimates of transport in previous works.

The variation of sea level difference across TwS is well correlated to the variation of volume transport through the TwS, $Q_{g}=6.07 *(\mathrm{SLD}-0.1)$. The contribution ratio of the surface geostrophic current variation, which is related to the sea level difference variation, to the variation of vertically averaged total volume transport is found about $73 \%$ of the variation of barotropic frictionless geostrophic flow case. The observed velocity profile is nearly barotropic except with lower speed near the bottom, hence the ratio is high but less than $100 \%$. The relation between the sea level difference and the volume transport is also found seasonally stable, unlike in the Tsushima Strait, located downstream of the Taiwan Warm Current. 
The high correlation between along-strait wind $T_{a}$, volume transport $Q$ and the sea level difference would suggest that the along-strait wind $T_{a}$ would drive the sea level difference across TwS and eventually change the volume transport of the geostrophic flow through the TwS. The 5- to 10-hour temporal lag of the transport $Q$ to $T_{a}$ would be explained by piling up time of the Ekman transport at the Strait's boundaries (Gill, 1982). The similar temporal lags of the sea level difference to $T_{a}$ (not shown) also support this idea. Details of the generation mechanisms of the wind-driven transport in TwS will be discussed in another paper.

\section{Appendix: Error Analysis of Velocity Measurements and Transport Estimates}

The errors in the estimated daily transport are from (1) the bias and random error in the ADCP measured velocity, (2) the removal of tidal current, and (2) the reduction of random errors by integration.

According to the manual of ADCP with $300 \mathrm{kHz}$ working frequency, the velocity uncertainty of one ping is $1.05 \mathrm{~mm} / \mathrm{s}$ for 4 meter bins, and it is $1.05 / \mathrm{sqrt}(\mathrm{N}) \mathrm{mm} / \mathrm{s}$ for the average of $\mathrm{N}$ ping. The accuracy of velocity is $\pm 0.5 \%$ of the water velocity (relative to the ADCP), $\pm 5 \mathrm{~mm} / \mathrm{s}$. A typical ping rate is $2 \mathrm{~Hz}$, one for measuring water velocity, and the other for measuring bottom depth and bottom velocity. So, the ADCP data rate is $1 \mathrm{~Hz}$.

The inaccuracy (bias) of ADCP data is unlikely to cause much problem, because the ferry runs a round trip in one day, and it reverses its cruise line every other day (clockwise in one day, counter-clockwise in the next day, and vice versa). If $0.5 \%$ of ship velocity enters ADCP data at one point during westbound leg, the same $0.5 \%$ will enter ADCP data in the eastbound leg, and they nearly cancel each other in daily averages. Besides, this error is mostly in the cross-strait direction, which is perpendicular to the along-strait direction of volume transport.

The maximal cruise speed is 17 knots, while the average speed is around 15 knots, or $7.65 \mathrm{~m} / \mathrm{s}$. The vertically averaged velocity $\underline{\mathrm{U}}$ is further averaged over 0.01 longitude bin, or $1207 \mathrm{~m}$ along the line 35 degree clockwise from the west. It takes about 129 second to sail through this bin, or 129 profiles per bin. In a rough sea, the rate of good data is $70 \%$ or more to be acceptable for further averaging. The average 
depth is about $60 \mathrm{~m}$ across TwS, ADCP can measure the water velocity from $8 \mathrm{~m}$ below sea surface to $8 \mathrm{~m}$ above sea bottom for $4 \mathrm{~m}$ depth bin of ADCP data. It means that there are about (60-8-8)/4=11 data per ping. So, each $\underline{\mathrm{U}}$ is the average of $129 * 0.7 * 11 \sim 993$ data or more. The uncertainty is $1.05 / \operatorname{sqrt}(993) \sim$ $0.033 \mathrm{~mm} / \mathrm{s}$ along the acoustic beam of ADCP. Because the beam is 20-degrees from the vertical, the derived horizontal velocity $\underline{\mathrm{U}}$ has the uncertainty of $0.0965 \mathrm{~mm} / \mathrm{s}$, or $7 \mathrm{~m}^{3} / \mathrm{s}$ transport uncertainty in a 0.01 longitudinal bin of $60 \mathrm{~m}$ depth. The randomness nature of $\underline{\mathrm{U}}$ assures that the volume transport $Q_{a d c p}$ (cross-strait integration of $\underline{\mathrm{U}}$ ) and its monthly mean have even smaller uncertainty, percentagewise.

The major uncertainty of $\underline{\mathrm{U}}$ is from the uncertainty of barotropic tidal velocity, $\underline{\mathrm{U}}_{t}$ in the barotropic tidal model TPXO. Ray (2001) concluded that (1) $\underline{\mathrm{U}}_{t}$ of TPXO agrees with $\underline{\mathrm{U}}_{\mathrm{t}}$ of other tidal models and with nearby moored current meter data where M2 amplitude is up to $30 \mathrm{~mm} / \mathrm{s}$ in the deep sea, and (2) TPXO is as good as other tidal models in simulating the barotropic tidal current components. In comparing TPXO against acoustic velocity measurement over a long distance, the difference is less than $2 \mathrm{~mm} / \mathrm{s}$ in the deep sea. The error is about $6.7 \%$ of the amplitude of $\mathrm{M} 2$ tidal current.

The M2 tidal current components $\left(\mathrm{u}_{\mathrm{t}}, \mathrm{v}_{\mathrm{t}}\right)$ from the harmonic analysis of the data set used by Teague et al. (2003) is $(190,170) \mathrm{mm} / \mathrm{s}$, which is nearly in phase with that from TPXO, but $10 \mathrm{~mm} / \mathrm{s}$ higher. This difference is about $5.5 \%$ of the amplitude which is in accord with $6.7 \%$ in the deep sea case (Ray, 2001). In the following, S2 is assumed to have similar error (about 5.5\%) as M2 has in TwS.

Taima Ferry may cross a longitude at any phase of M2 tidal current. The daily round trip of the ferry crossing TwS spans two cycles of M2. At any point along the ship track, M2 tidal current contributes up to $\pm 10 \mathrm{~mm} / \mathrm{s}$ difference from that of Teague et al. (2003). Since this difference spans twice over all phases of M2 tide in one day and the phase at any location changes every day, therefore it cancels itself in the integration of velocity to get the transport $Q_{a d c p}$. This is true to all other tidal components, except S2 tidal current component.

Taima leaves Keelung Harbor at 22:00 to 22:30, returns around 16:30 for a counterclockwise cruise track in good weather, and around 18:30 for clockwise cruise track with severe sea state. It means that at any longitude, the westbound leg is nearly at fixed phase of S2 tidal current, only the eastbound leg varies a little in the phase of S2 tide. 
The amplitude of $\mathrm{S} 2$ tidal component is about $(80,65) \mathrm{mm} / \mathrm{s}$ from tidal analysis of the mooring data, those from TPXO is smaller by $10 \mathrm{~mm} / \mathrm{s}$ or less, and the error in removing $\mathrm{S} 2$ tidal current is less than $10 \mathrm{~mm} / \mathrm{s}$, or 5\%, at a fixed location. The average of such error across TwS covers two cycle of S2 current, is much smaller than $5 \%$ in computing the transport.

In sum, if the along-strait mean current is $1000 \mathrm{~mm} / \mathrm{s}$ and all the errors are synchronized (worst case), the vertical mean lateral velocity (nearly along strait direction) from daily of two ADCP data in a 0.01 longitudinal bin of, may have bias about $(0.5 \% * 1000+5) / \sin \left(20^{\circ}\right)=29.2 \mathrm{~mm} / \mathrm{s}$, and the uncertainty of barotropic velocity of each bin is about $0.1+10+10+2=22.1 \mathrm{~mm} / \mathrm{s}$, from data uncertainty, and from removing tidal components of $\mathrm{M} 2, \mathrm{~S} 2$, and all others (assumed $2 \mathrm{~mm} / \mathrm{s}$ ) at various tidal phases.

The mean depth of TwS is about $60 \mathrm{~m}$, the uncertainty of transport in a longitudinal bin is about $60 * 1207 * 0.0221 \sim 1600 \mathrm{~m}^{3} / \mathrm{s}$. The cruise line spans over 170 longitudinal bins with round trip, therefore the resulted uncertainty in $Q_{a d c p} \sim \operatorname{sqrt}(2 * 170) * 1600 \sim 0.03 \mathrm{~Sv}$ if the uncertainty has normal distribution, or $0.54 \mathrm{~Sv}$ if all uncertainties are synchronized.

The uncertainty in a year-long measurement is unlikely to be synchronized. There are about $180 Q_{a d c p}$ data in one year, the annual mean of $Q_{a d c p}$ has uncertainty less than $0.54 / \mathrm{sqrt}(180) \sim 0.04 \mathrm{~Sv}$, which is far less than the observed $1 \mathrm{~Sv}$ for standard deviation of $Q_{a d c p}$, which also contains standard deviation of the wind-driven transport through TwS.

Acknowledgments. We would like to thank the Lienjiang County Government for permission to install ADCP on their Taima Ferry and the crew of the Taima Ferry for the routine operation of the ADCP system. This research is supported by grants from the Office of Naval Research (Grant Number N62909-10-1-7154); the National Science Council of Taiwan (NSC 99-2611-M-002-012, NSC 100-2611-M-002-001, NSC 102-2611-M-015 -001); the Ministry of Education, Culture, Sports, Science and Technology-Japan (MEXT: Strategic Funds for the Promotion of Science and Technology); the Research Institute for Applied Mechanics, Kyushu University; and the Taiwan Ocean Research Institute. Support of this joint research project from National Taiwan University, Kyushu University, and the Central 
Police University of the ROC are also acknowledged.

\section{References}

Acker, J.G., Leptoukh, G., 2007. Online analysis enhances use of NASA Earth science data. Eos Trans. AGU. 88, p. 14 and p.17.

Buijsman, M.C., Ridderinkhof, H., 2007. Long-term ferry-ADCP observations of tidal currents in the Marsdiep inlet. J. Sea Res. 57, 237-256.

Candela, J., Beardsley, R.C., Limeburner, R., 1992. Separation of tidal and subtidal currents in shipmounted acoustic Doppler current profiler observations. J. Geophys. Res. 97, 769-788.

Carrillo, L., Souza, A.J., Hill, A.E., Brown, J., Fernand, L., Candela, J., 2005. Detiding ADCP data in a highly variable shelf sea: The Celtic Sea. J. Atmos. Oceanic Technol. 22, 84-97.

Chen, C.-T. A., 2003. Rare northward flow in the Taiwan Strait in winter: a note. Cont. Shelf Res. 23, $387-391$.

Egbert, G.D., Bennett, A.F., Foreman, M.G.G., 1994. TOPEX/POSEIDON tides estimated using a global inverse model. J. Geophys. Res. 99, 24821-24852.

Egbert, G.D., Erofeeva, S.Y., 2002. Efficient inverse modeling of barotropic ocean tides. J. Atmos. Oceanic Tech. 19, 183-204.

Erofeeva, S.Y., Padman, L., Egbert, G., 2005. Assimilation of ship-mounted ADCP data for barotropic tides: Application to the Ross Sea. J. Atmos. Oceanic Tech. 22, 721-734.

Fang, G., Zhao, B., Zhu, Y., 1991. Water volume transport through the Taiwan Strait and the continental shelf of the East China Sea measured with current meters, in Takano, K. (Eds.), Oceanography of Asian Marginal Seas, Elsevier, New York, 345-358.

Foreman, M.G.G., Freeland, H.J., 1991. Comparison of techniques for tide removal from ship-mounted acoustic Doppler measurements along the southwest coast of Vancouver Island. J. Geophys. Res. 96, $17007-17021$. 
Geyer, R., Signell, R., 1990. Tidal flow measurement around a headland with a shipboard acoustic Doppler current profiler. J. Geophys. Res. 95, 3189-3197.

Gill, A.E., 1982. Atmosphere-Ocean Dynamics. Academic Press, London, UK.

Guan, B., 1986. Evidence for a counter-wind current in winter off the southeast coast of China. Chinese J. Oceanol. Limnol. 4, 319-332.

Hu, J., Kawamura, H., Li, C., Hong, H., Jiang, Y., 2010. Review on current and seawater volume transport through the Taiwan Strait. J. Oceanogr. 66, 591-610.

Isobe, A., 2008. Recent advances in ocean-circulation research on the Yellow Sea and East China Sea shelves. J. Oceanogr., 64, 569-584.

Jan, S., Wang, J., Chern, C.-S., Chao, S.-Y., 2002. Seasonal variation of the circulation in the Taiwan Strait. J. Mar Syst. 35, 249-268.

Jan, S., Chao, S.-Y., 2003. Seasonal variation of volume transport in the major inflow region of the Taiwan Strait: the Penghu Channel. Deep Sea Res. II. 50, 1117-1126.

Jan, S., Tseng, Y.-H., Dietrich, D. E., 2010. Sources of water in the Taiwan Strait. J. Oceanogr. 66, 211-221.

Katoh, O., Teshima, K., Kubota, K., Tsukiyama, K., 1996. Downstream transition of the Tsushima Current west of Kyushu in summer. J. Oceanogr. 52, 93-108.

Ko, D., Preller, R., Jacobs, G., Tang, T., Lin, S., 2003. Transport reversals at Taiwan Strait during October and November 1999. J. Geophys. Res. 108, DOI: 10.1029/2003JC001836.

Lee, M.A., Yang, Y.C., Shen, Y.L., Chang, Y., Tsai, W.S., Lan, K.W., Kuo, Y.C., 2014. Effects of an unusual cold-water intrusion in 2008 on the catch of coastal fishing methods around Penghu Islands, Taiwan. Terr. Atmos. Ocean. Sci. 25, 107-120.

Liao, E., Jiang, Y., Li, L., Hong, H., Yan, X., 2013. The cause of the 2008 cold disaster in the Taiwan Strait. Ocean Modell. 62, 1-10.

Lin, S., Tang, T., Jan, S., Chen, C.-J., 2005. Taiwan Strait current in winter. Cont. Shelf Res. 25, $1023-1042$. 
Liu, K.-K., Tang, T.Y., Gong, G.-C., Chen, L.-Y., Shiah, F.-K., 2000. Cross-shelf and along-shelf nutrient fluxes derived from flow fields and chemical hydrography observed in the southern East China Sea off northern Taiwan. Cont. Shelf Res. 20, 493-523.

Münchow, A., 2000. Detiding three-dimensional velocity survey data in coastal waters. J. Atmos. Oceanic Tech. 17, 736-748.

Niwa, Y., Hibiya, T., 2004. Three-dimensional numerical simulation of $\mathrm{M}_{2}$ internal tides in the East China Sea. J. Geophys. Res. 109, C04,027.

Pawlowicz, R., Beardsley, B., Lentz, S., 2002. Classical tidal harmonic analysis including error estimates in MATLAB using T_TIDE. Comput. Geoscì. 28, 929-937.

Ray, R.D., 2001. Inversion of oceanic tidal currents from measured elevations. J. Mar Syst. 28, 1-18.

Takikawa, T., Yoon, J.-H., 2005. Volume transport through the Tsushima Straits estimated from sea level difference. J. Oceanogr. 61, 699-708.

Teague, W.J., Jacobs, G.A., Ko, D.S., Tang, T.Y., Chang, K.-I., Suk, M.-S., 2003. Connectivity of the Taiwan, Cheju, and Korea straits. Cont. Shelf Res. 23, 63-77

Wang, Y., Jan, S., Wang, D., 2003. Transports and tidal current estimates in the Taiwan Strait from shipboard ADCP observations (1999-2001). Estuar. Coast. Shelf Sci. 57, 193-199.

Wu, C.-R., Hsin, Y.-C., 2005. Volume transport through the Taiwan Strait: A numerical study. Terr. Atmos. Ocean Sci. 16, 377-391.

Wu, C.-R., Chao, S.-Y., Hsu, C., 2007. Transient, seasonal and interannual variability of the Taiwan Strait current. J. Oceanogr. 63, 821-833.

Wyrtki, K., 1961. Scientific results of marine investigations of the South China Sea and the Gulf of Thailand, 1959-1961. Naga Report 2, 195 pp., Scripps Institution of Oceanography.

Yang, J., 2007. An oceanic current against the wind: How does Taiwan Island steer warm water into the East China Sea? J. Phys. Oceanogr. 37, 2563-2569.

Zhao, B., Fang, G., 1991. Estimation of water volume transports through the main straits of the East China Sea. Acta Oceanol. Sin. 10, 1-13. 
Zhu, J., Chen, C., Ding, P., Li, C., Lin, H., 2004. Does the Taiwan Warm Current exist in winter? Geophys.

Res. Lett. 31, L12, 302.

\section{Figure Captions}

Fig. 1. The geography and topography along the Taima Ferry cruise track across TwS. Pengiiayu is the weather station to provide the wind data. Tide gauge stations at Mailiao and Kinmen measure the sea level height respectively. Taima Ferry sails either clockwise or counterclockwise between Keelung, Matsu, and Dongyin. The departure times at Keelung and Matsu are usually at 22:00 and 09:30, and it takes about $8.5 \mathrm{~h}$ from Keelung to Matsu, about $8 \mathrm{~h}$ to Dongyin, and $2.5 \mathrm{~h}$ for Matsu-Dongyin leg.

Fig. 2. A snapshot of current velocity field along the track: (a) the along-strait ( $U_{a}$, northeastward) and (b) cross-strait $\left(U_{c}\right.$, southeastward) velocity components of the residual current velocity $\boldsymbol{U}_{\boldsymbol{r}}(x, y, z, t)$ between

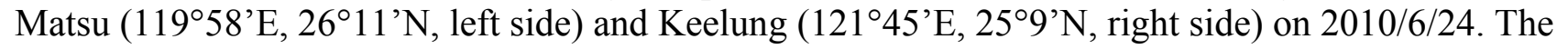
contour intervals are in steps of $0.1 \mathrm{~m} / \mathrm{s}$, and the zero-contour is marked with a thick curve. In the main (eastern) part of TwS, $U_{a}$ is positive (towards ECS), except near the Taiwan coast. The value of $U_{c}$ in the eastern half of TwS is nearly zero, except for the bottom layer at the eastern end of the cruise line, where a deep inflow balances the entrainment by the outflow above mid-depth. (c) $U_{a}$ and (d) $U_{c}$ across TwS at two depths, $11.2 \mathrm{~m}$ and $35.2 \mathrm{~m}$. In the western half of TwS, $U_{c}$ is negative, which means that the coastal current flows towards the China coast near Matsu.

Fig. 3. Bi-monthly vertically averaged residual (de-tided) current velocity along the track of Taima Ferry in 2009-2011.

Fig. 4. Three-year (2009-2011) bi-monthly mean of (a) the along-strait, residual (de-tided) current velocity $U_{a}$ between Keelung and Matsu and (b) the vertical averages of $\boldsymbol{U}_{\boldsymbol{r}}$ with depth contours at 50, 100, 150, and $200 \mathrm{~m}$.

Fig. 5. Daily observed $Q_{a d c p}$. The symbols in the top panel mark the days of observation.

Fig. 6. (a) Wind of 2009-2011 at Pengjiayu (PJY) weather station. It is low-passed with a 40-h moving average. (b) Regression relation between the along-strait wind velocity from PJY (abscissa, daily mean of hourly data) and that from the analysis of satellite scatterometer wind data (ordinate, approximately 1 datum per day) near cruise line. The wind velocity scale is shown with both the eastward and northward velocity components being $5 \mathrm{~m} / \mathrm{s}$. Data in summer (winter) are plotted with cross (plus) signs.

Fig. 7. Cross-correlation coefficient $\gamma$ between the volume transport $Q$ and the along-strait wind stress $T_{a}$ for various directions (clockwise from North) and the lags of the 23-h mean $T_{a}$ from 08:20, the mean time of day for $Q$. The along-strait direction is selected as $35^{\circ}$, where $\gamma$ is near its maximum.

Fig. 8. (a) Regression of $Q_{a d c p}$ (the observed $Q$ ) vs. the along-strait wind stress $T_{a}$. The daily mean $Q$ may be estimated as $Q_{e}=2.00+16.03 T_{a}$. Data in southwesterly winds (summer monsoon) and northeasterly winds (winter monsoon) are plotted with asterisks (crosses). (b) Observed $Q_{a d c p}$ and the gap-filled $Q_{f}: Q_{f}$ equals $Q_{a d c p}$, or the estimated $Q_{e}$ at gaps of $Q_{a d c p}$. The dates of $Q_{a d c p}$ are indicated on the top of the figure.

Fig. 9. (a) Seven-day means of $Q_{f}$ in 2009, 2010, and 2011 and their annual mean values. (b) Monthly mean of $Q_{f}$, the cosine fit $Q_{t}$ of $Q_{f}$ is compared to the cosine fit $Q_{i}$ by Isobe (2008). 
Fig. 10. (a) Daily average wind velocity at Pengjiayu for the year 1997. (b) Daily average $T_{a}$ at Pengjiayu in March 1997. The cruise of Liu et al. (2000) was conducted during anomalous southerly wind on March 5-6 in the northeasterly monsoon season. (c) Revised (thick arrow) transport for L00 by Liu et al. (2000) as shown in Fig. 10 of Isobe (2008). Other markings are published transport values by authors and years, e.g. W03 means Wang et al. (2003), J06 means Jan et al. (2006), Z91 means Zhao and Fang (1991), F91 means Fang et al. (1991).

Fig. 11. Observed daily $Q$ (dots), weekly mean $Q_{f}$ (green), and monthly mean $Q_{f}$ (magenta) through TwS. The black line is the estimated $Q_{e}$ from Eq. (2) and the composite of the 30-day moving average of wind stress $T_{a}$ during 2009/1/1 2011/12/31. Q7day composite is the average of the three curves in Fig. 9a.

Fig. 12. Scatter plots for $Q_{a d c p}$ and the sea level difference across central TwS. Data in summer (winter) monsoon are plotted with crosses (pluses). Outliers whose SLD $<-0.5 \mathrm{~m}$ are removed in the figure.

Fig. 13. MODIS-derived PIC concentration $\left(\mathrm{mol} / \mathrm{m}^{3}\right)$ for February 2010 (Acker and Leptoukh, 2007). White areas lack data. The open ocean water has low PIC in green and blue areas. 


\section{Figure1}
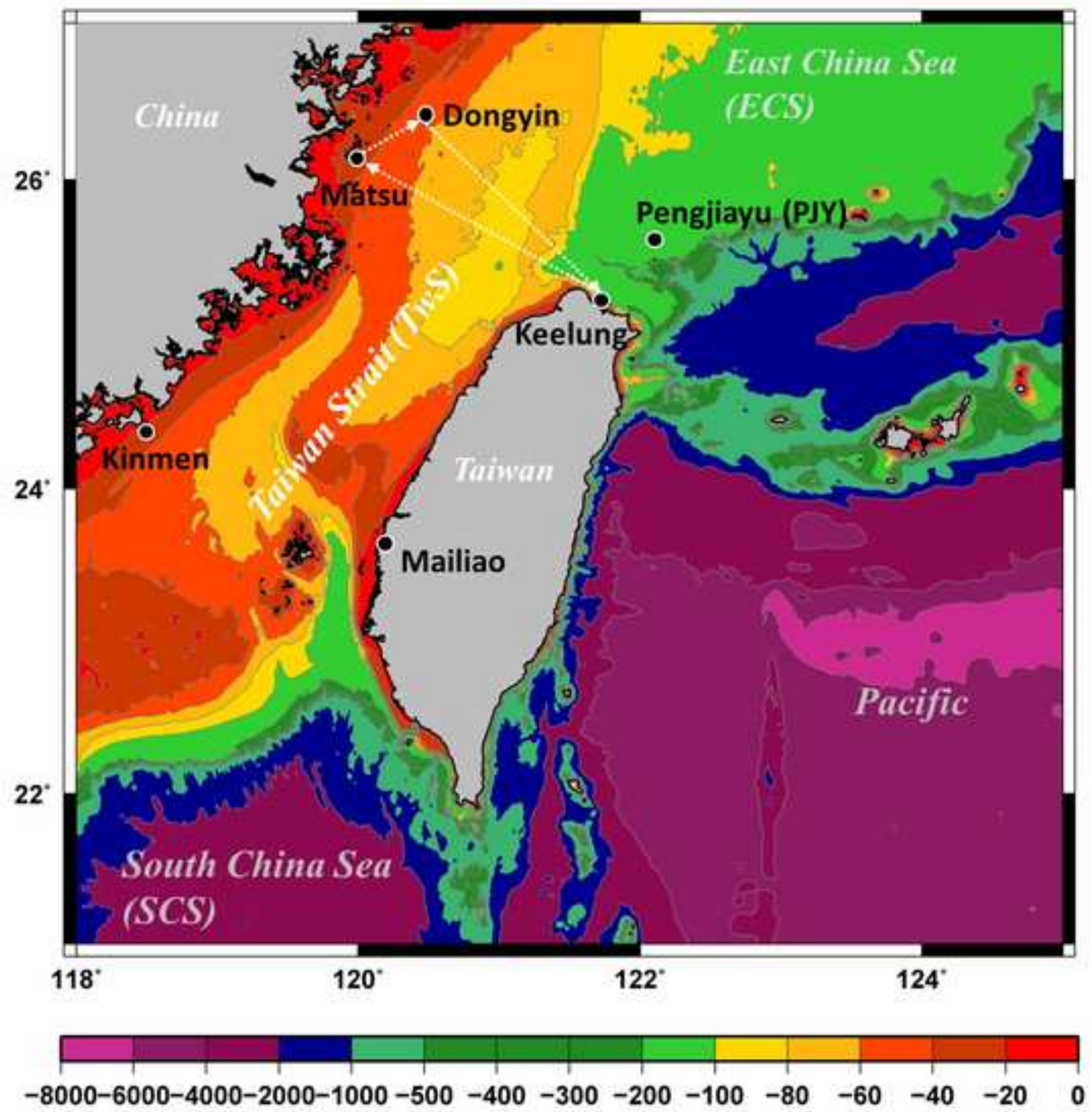
(a)

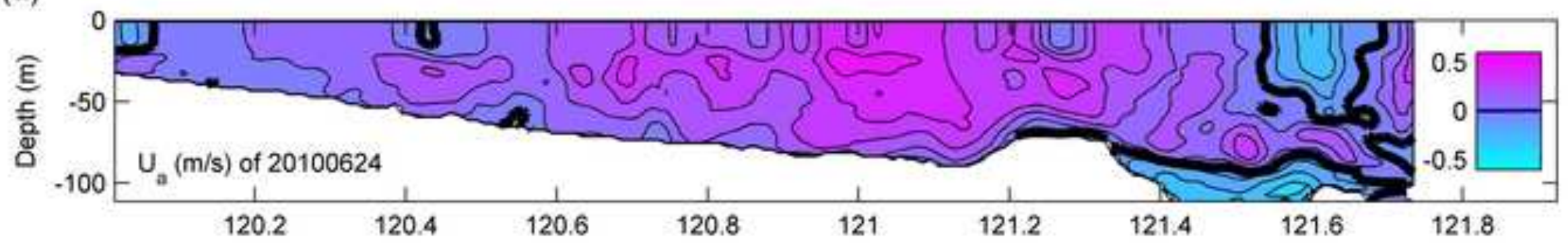

(b)

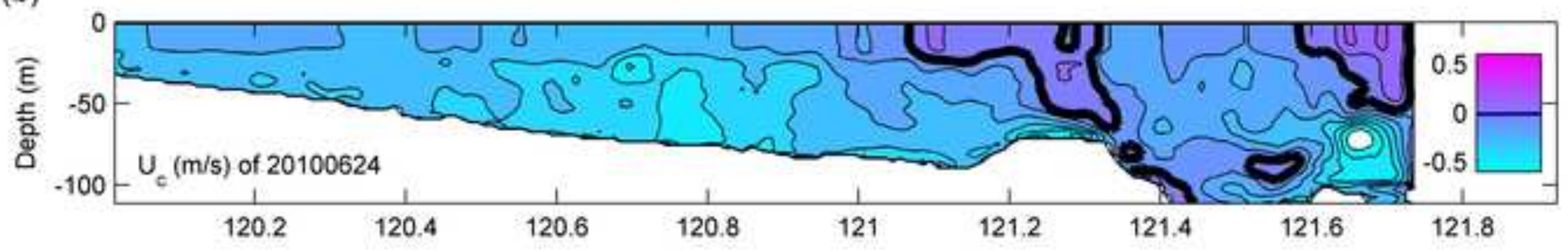

(c)

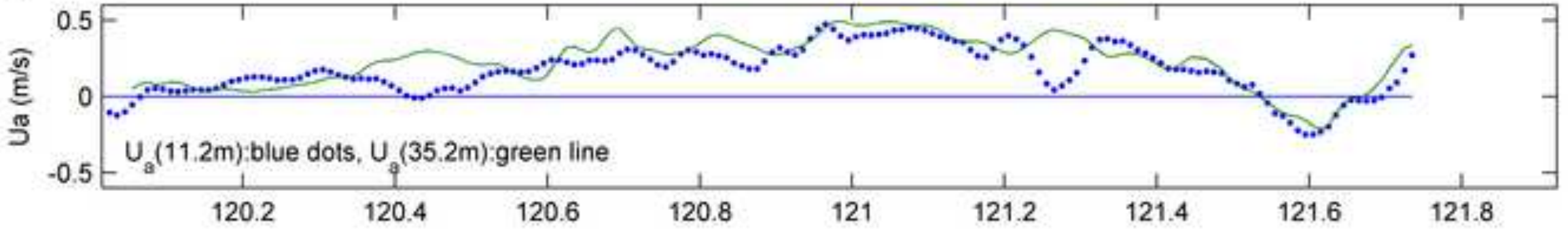

(d)

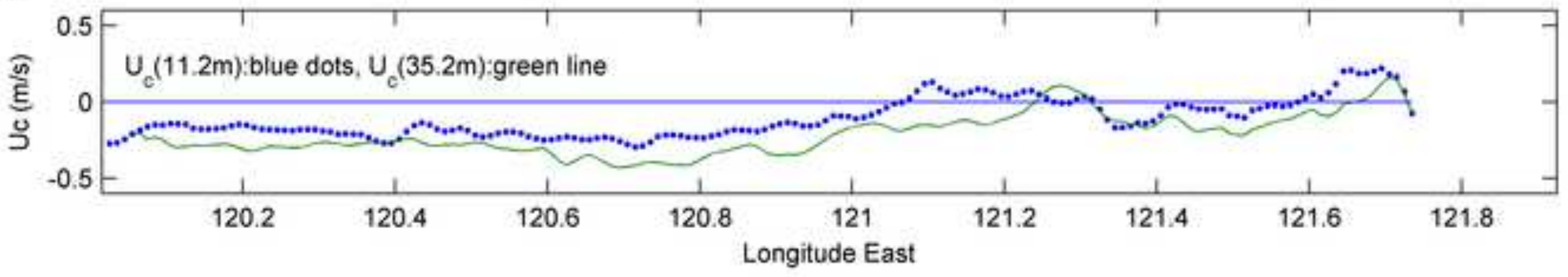




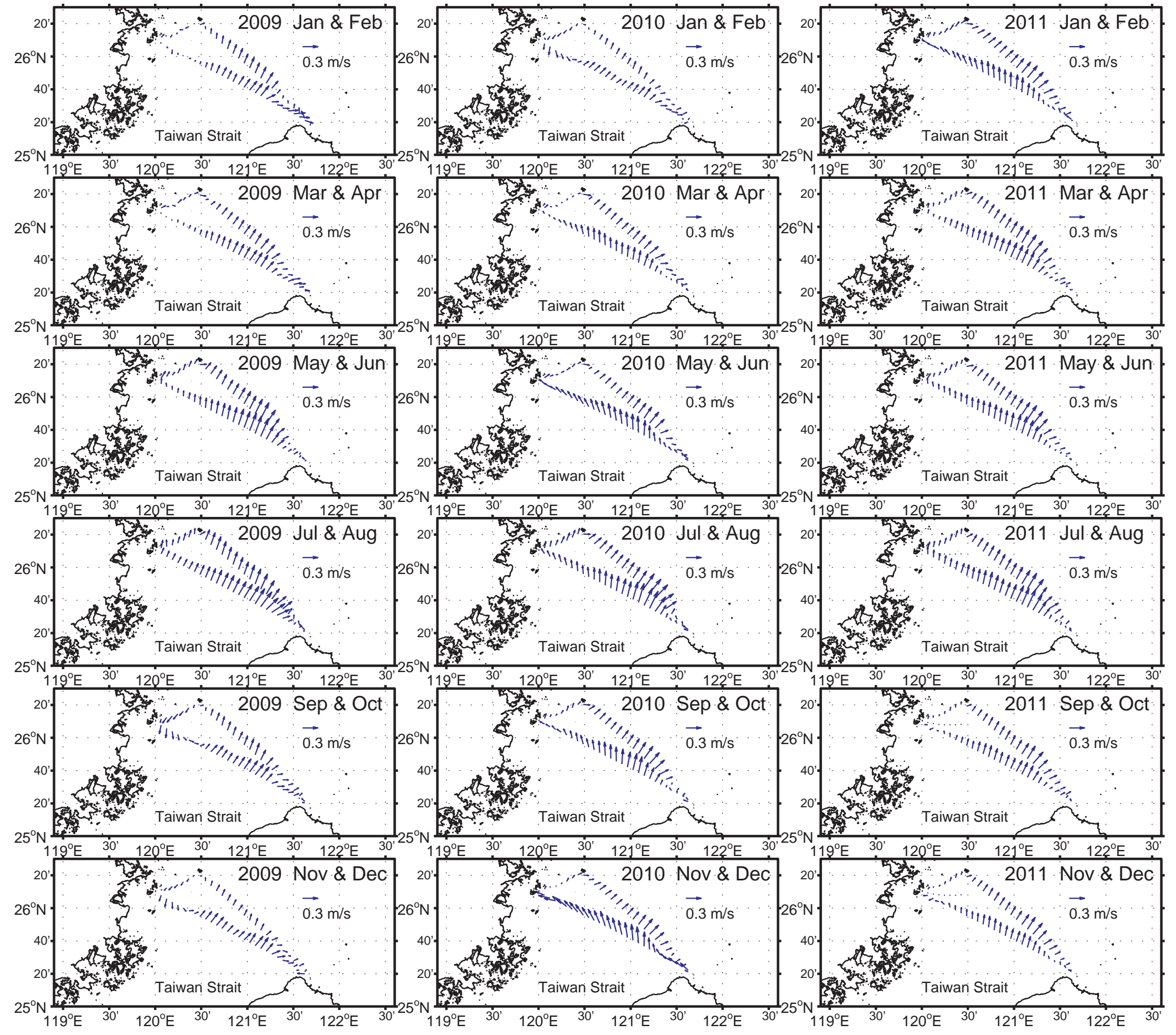




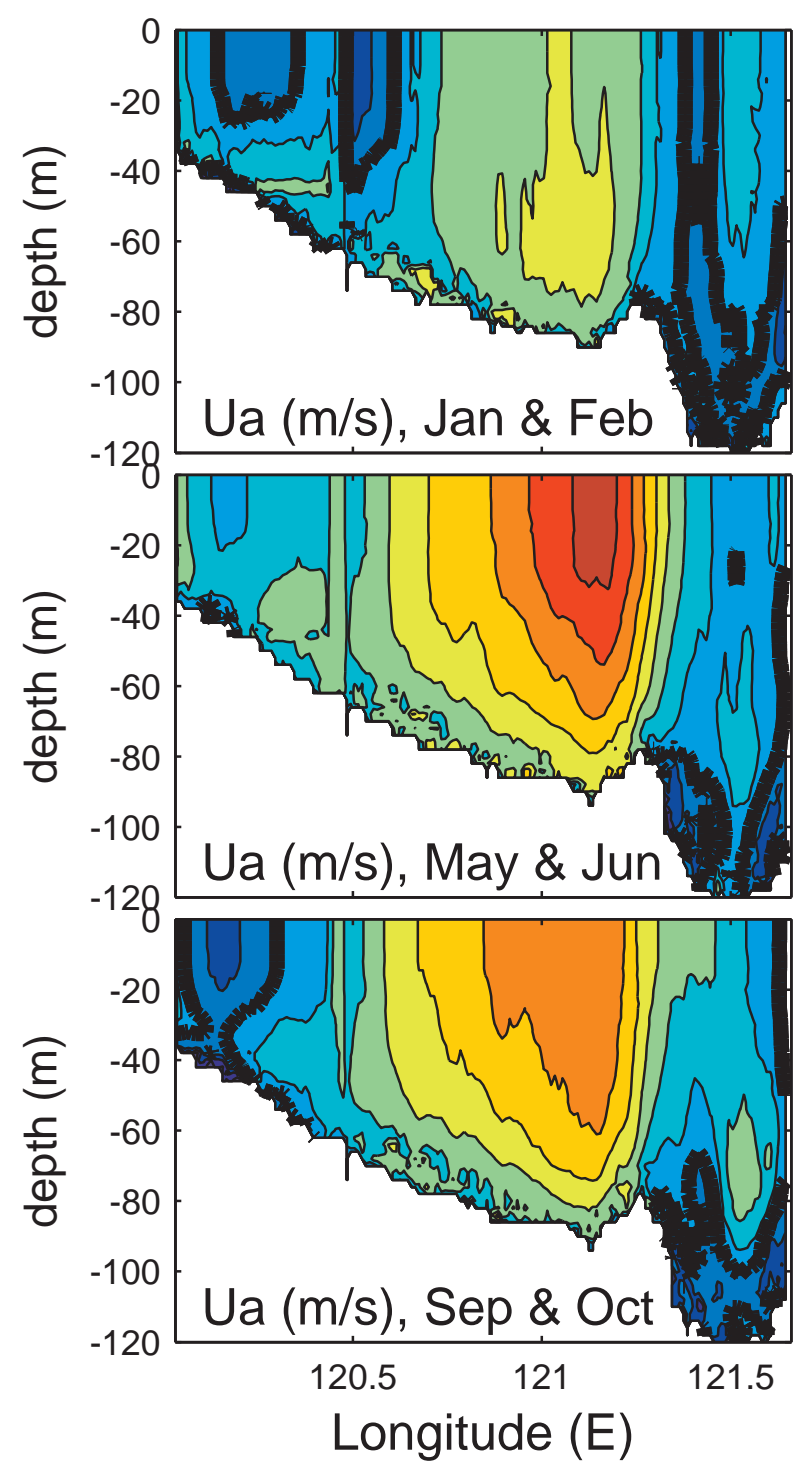

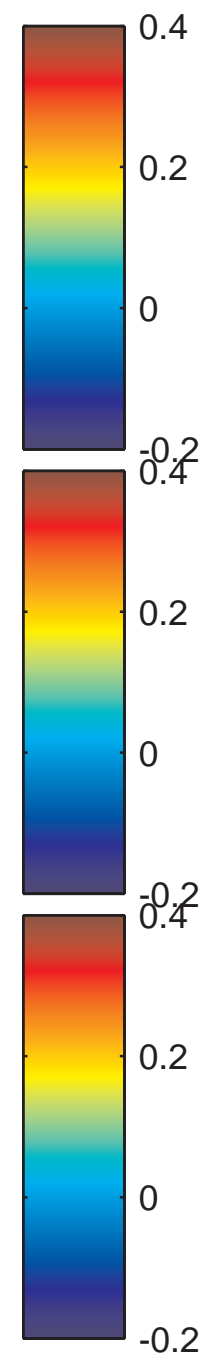

$-0.2$
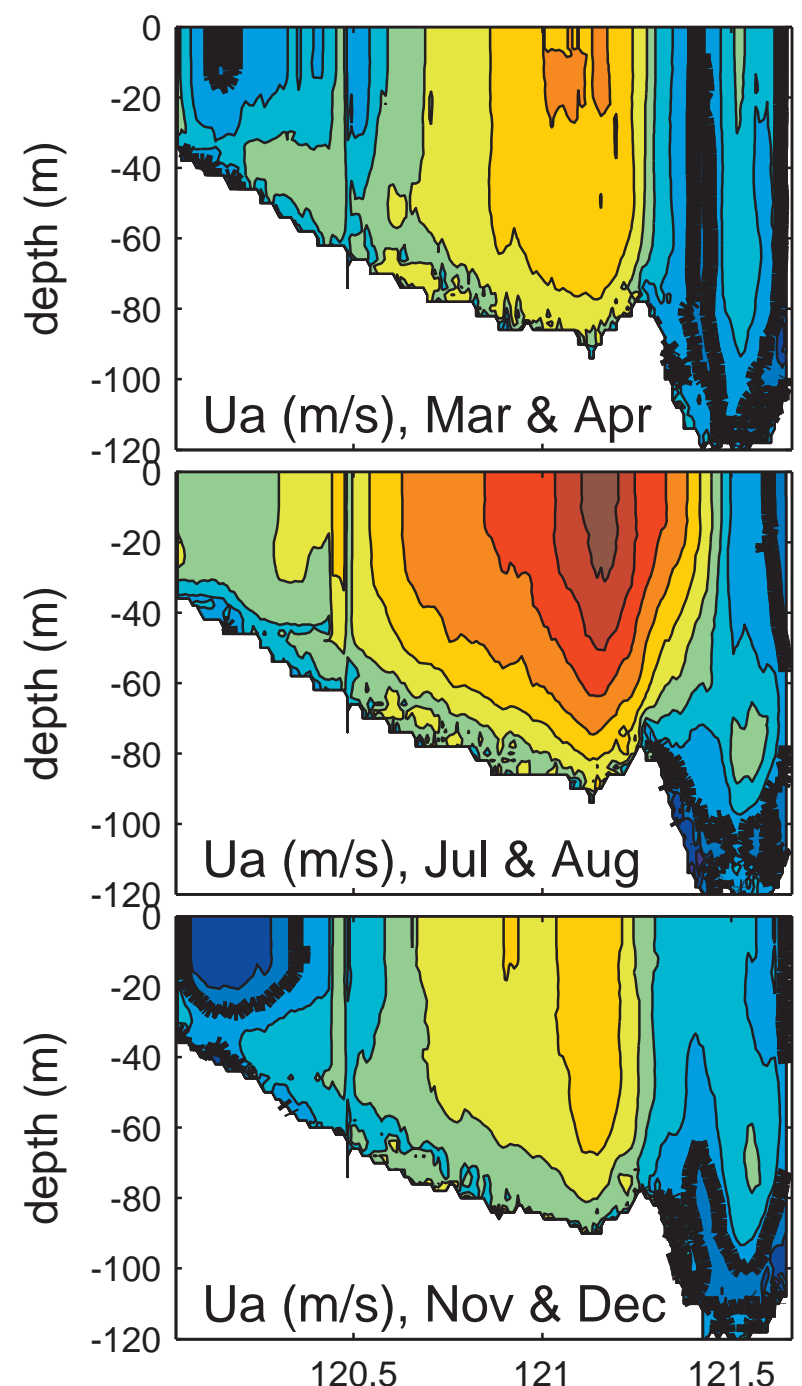

Longitude (E)

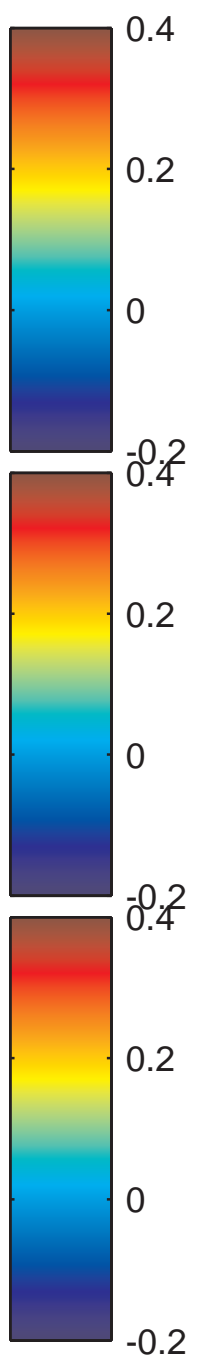



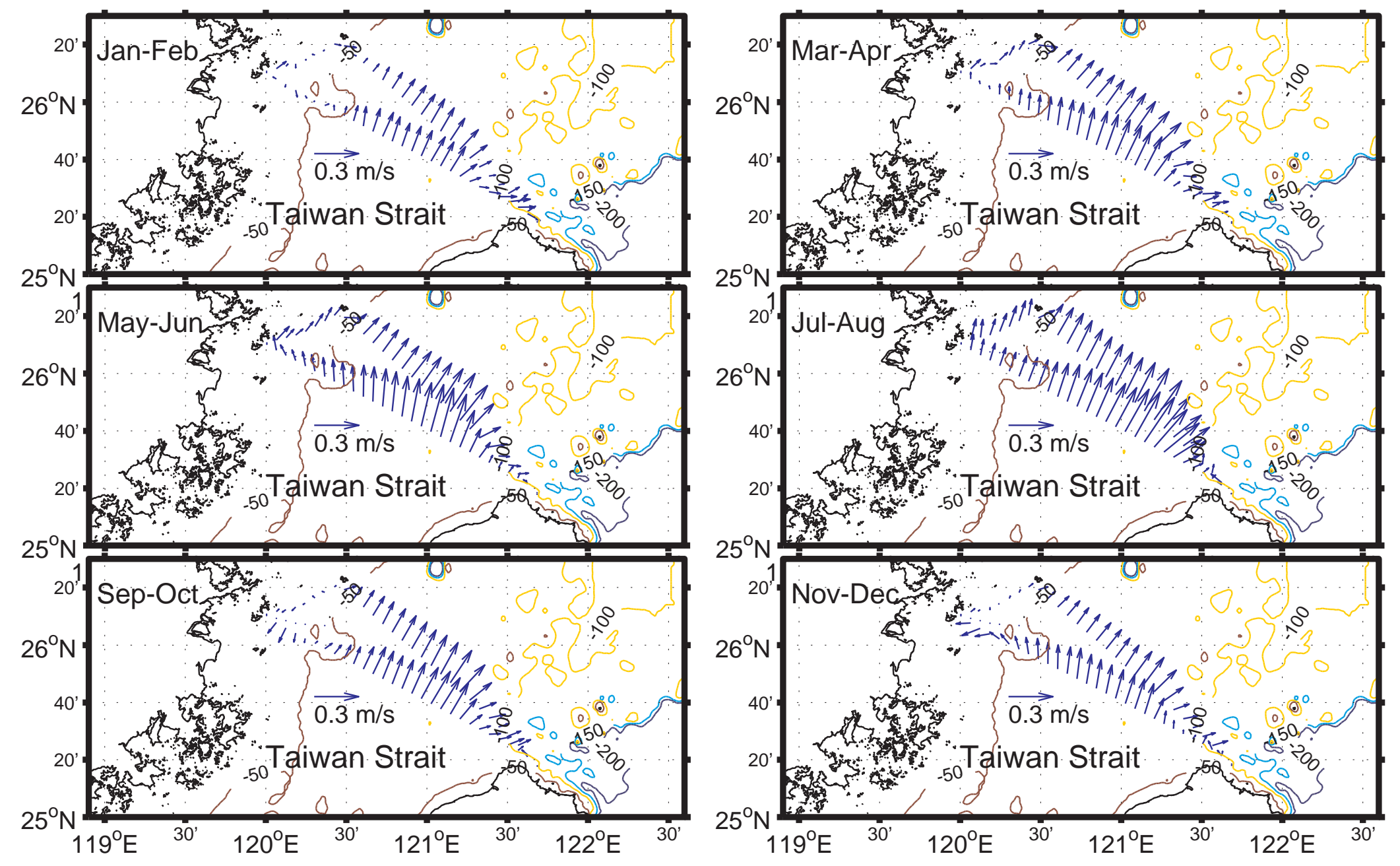


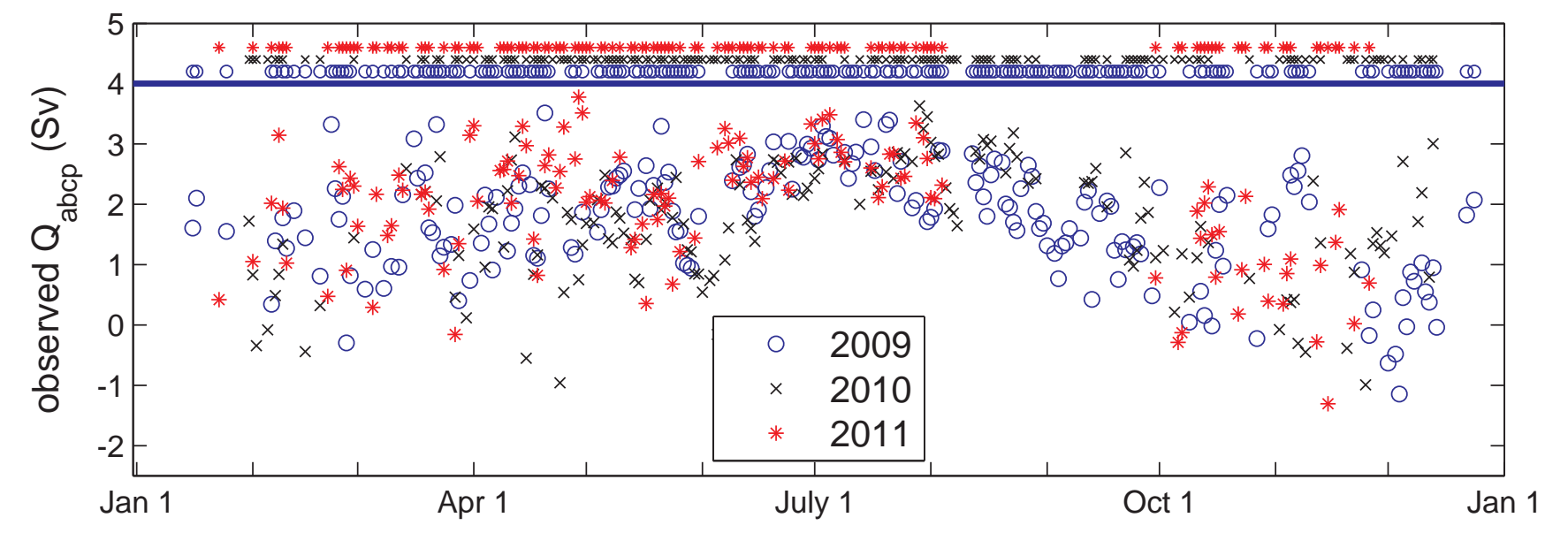

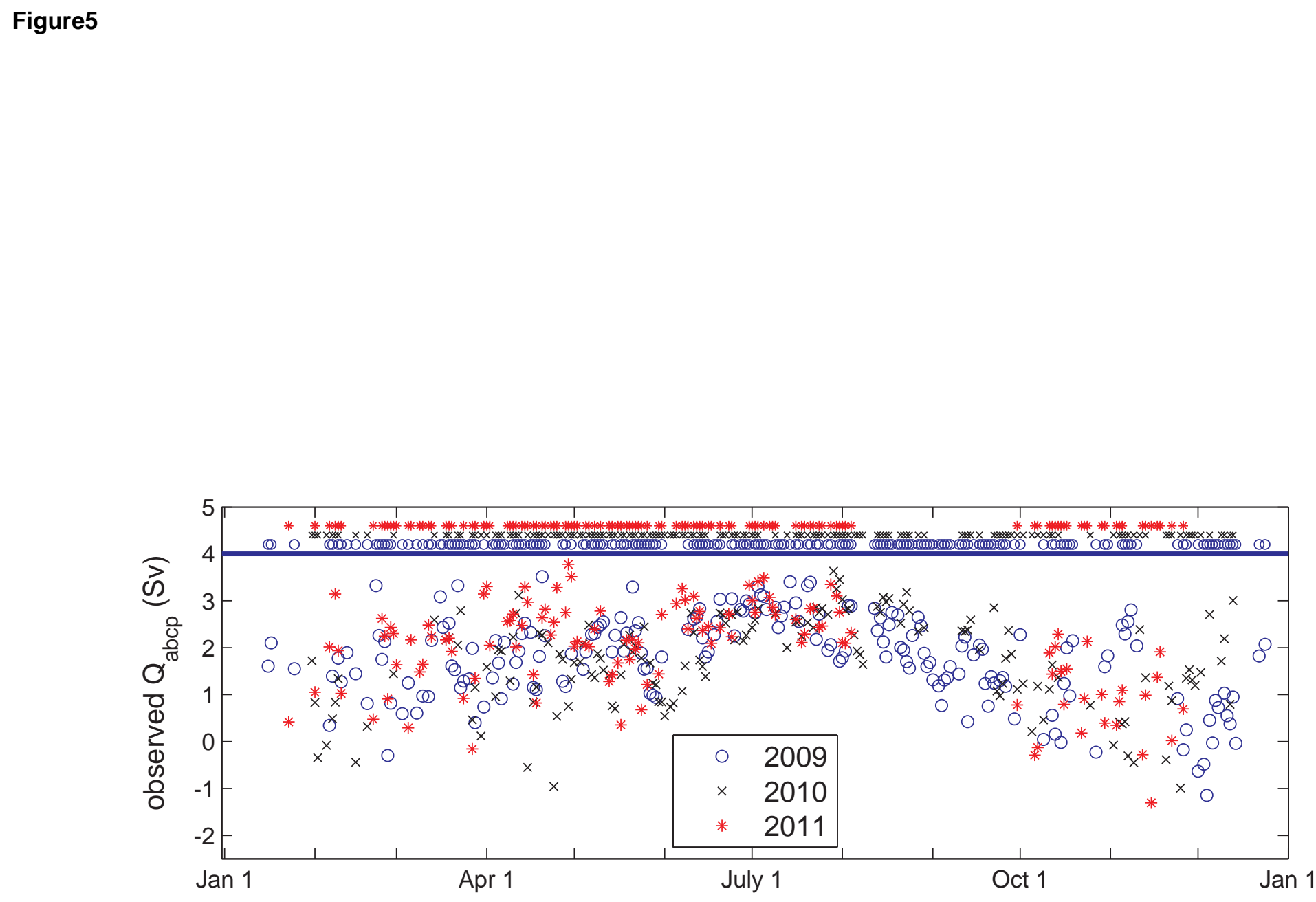

$$
\text { Apr } 1
$$

Oct 1 
(a) wind at Pengjiayu

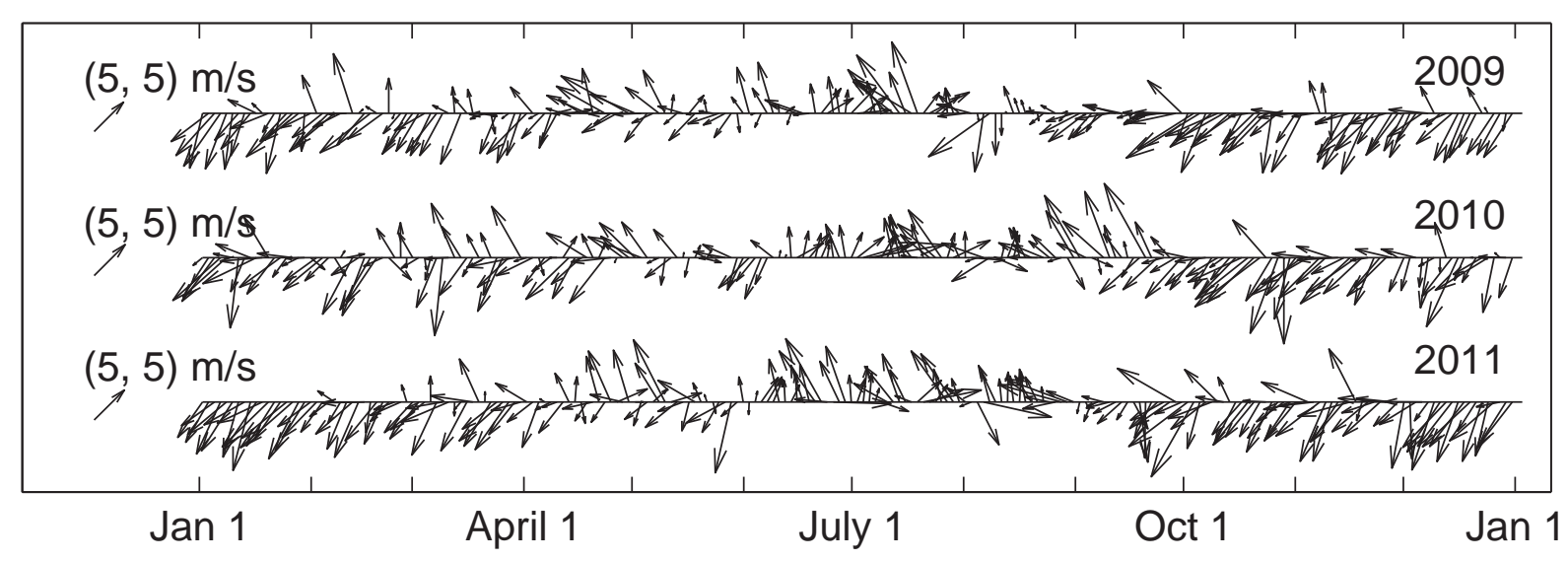


(b) Sat wind $=1.01^{*} \mathrm{PJY}$ wind $-2.4 \mathrm{~m} / \mathrm{s}$, corr coef $=0.82$

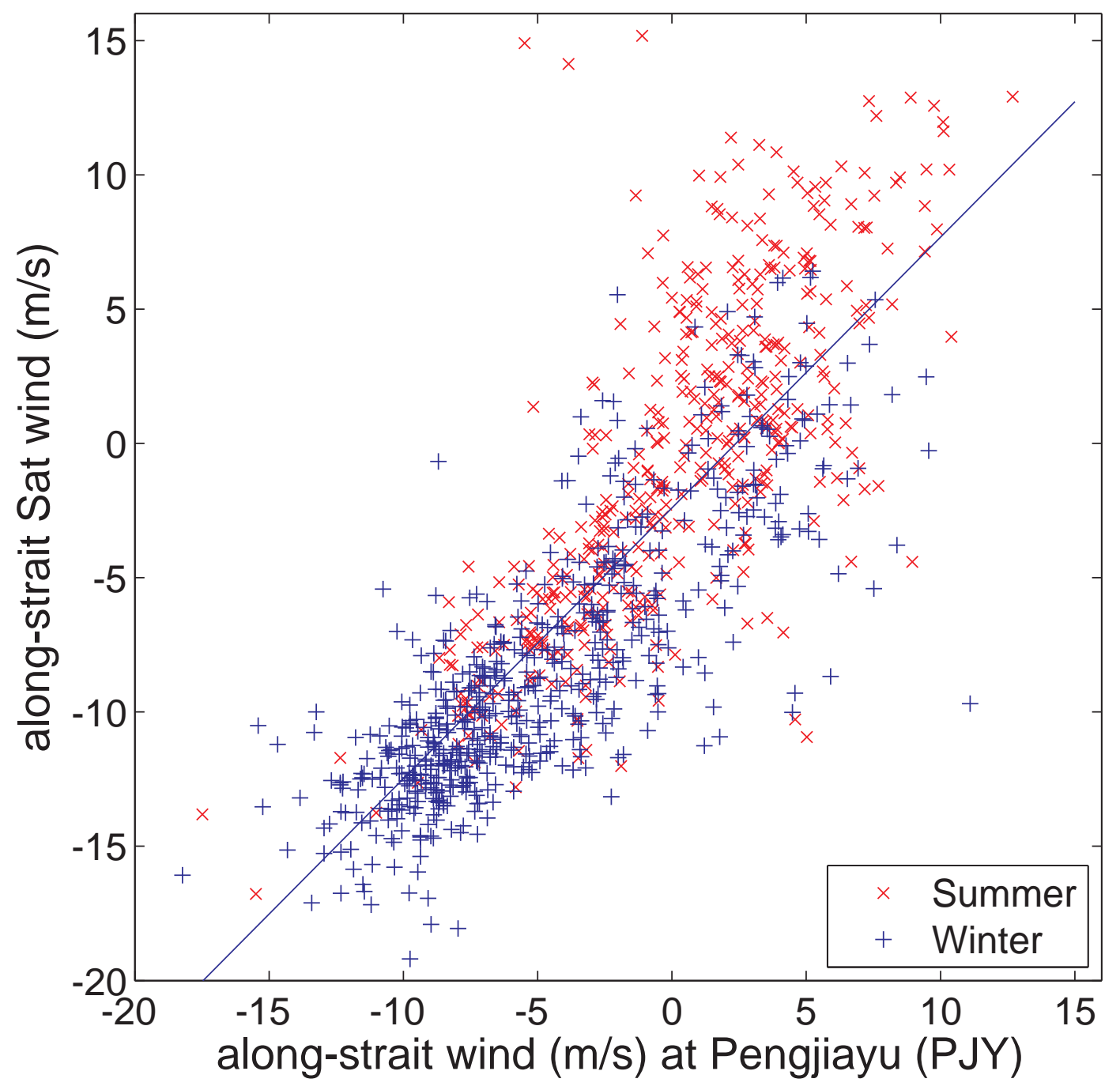




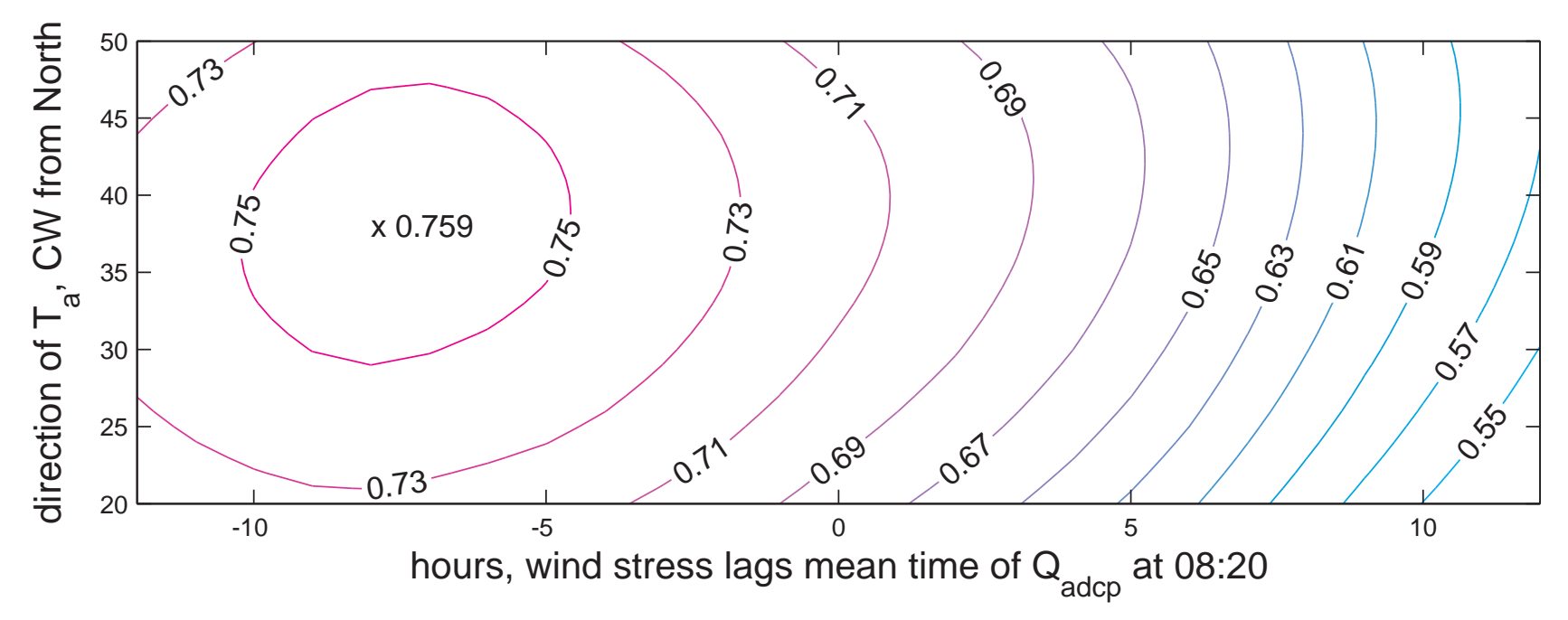

Figure7 
(a) estimated transport, $Q_{e}=2+16.03^{*} T_{a}$, corr coeff $=0.76$

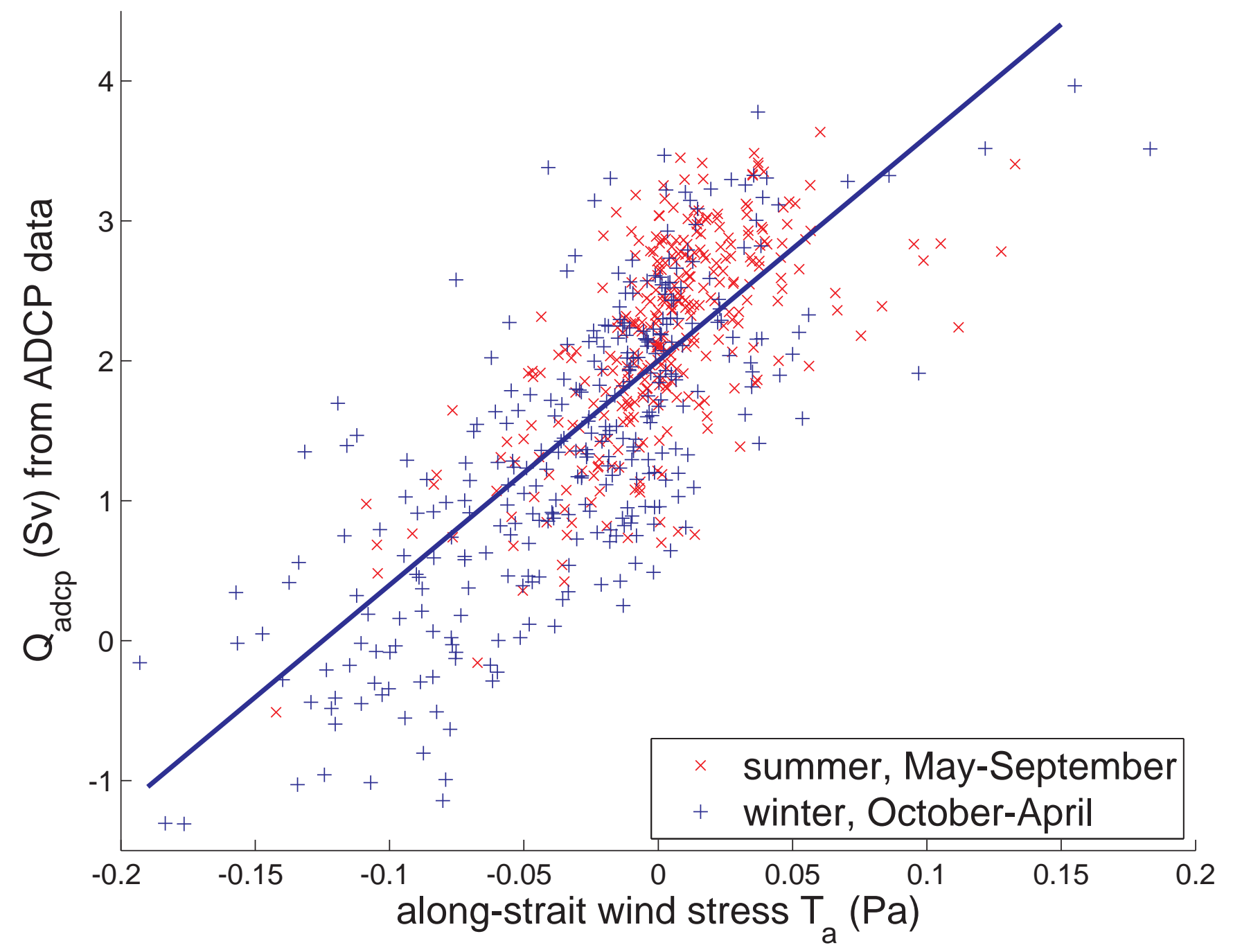


(b)

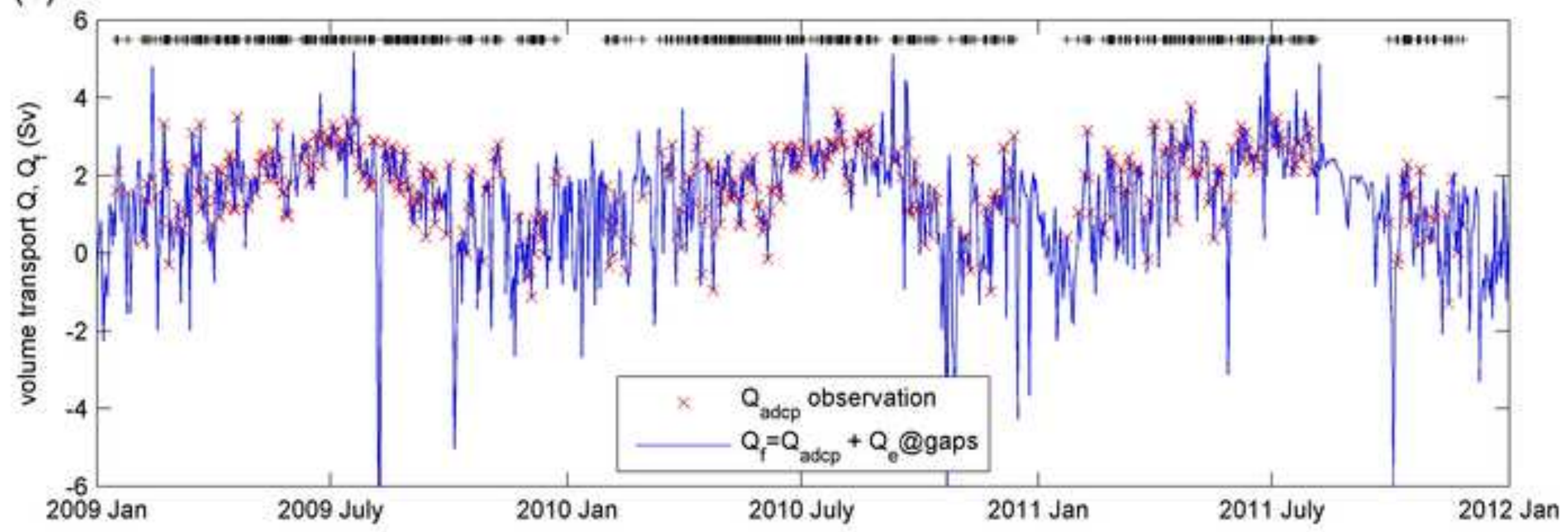




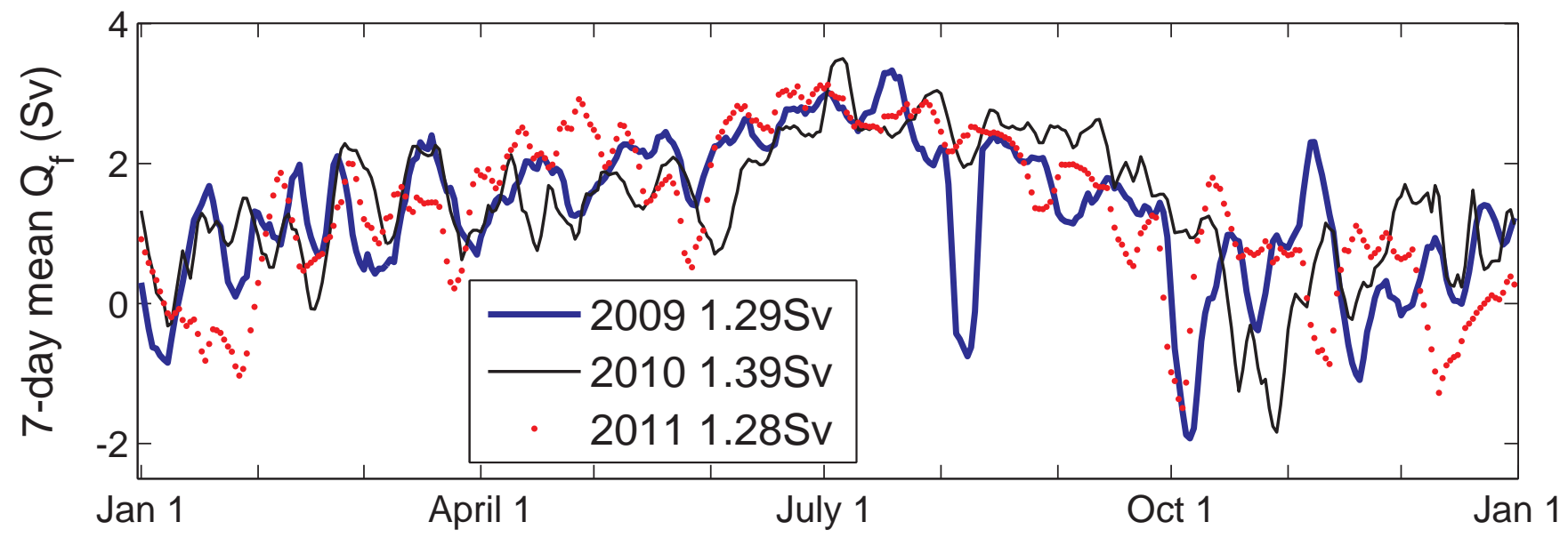

Figure9a 


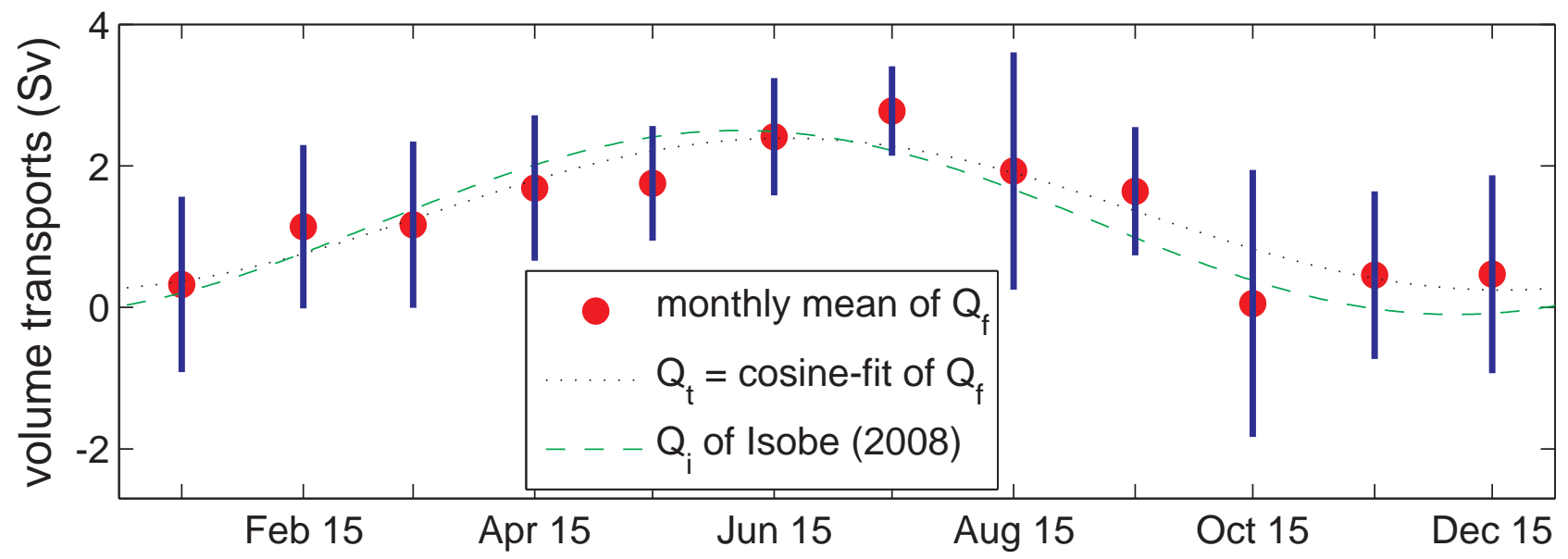

Figure9b
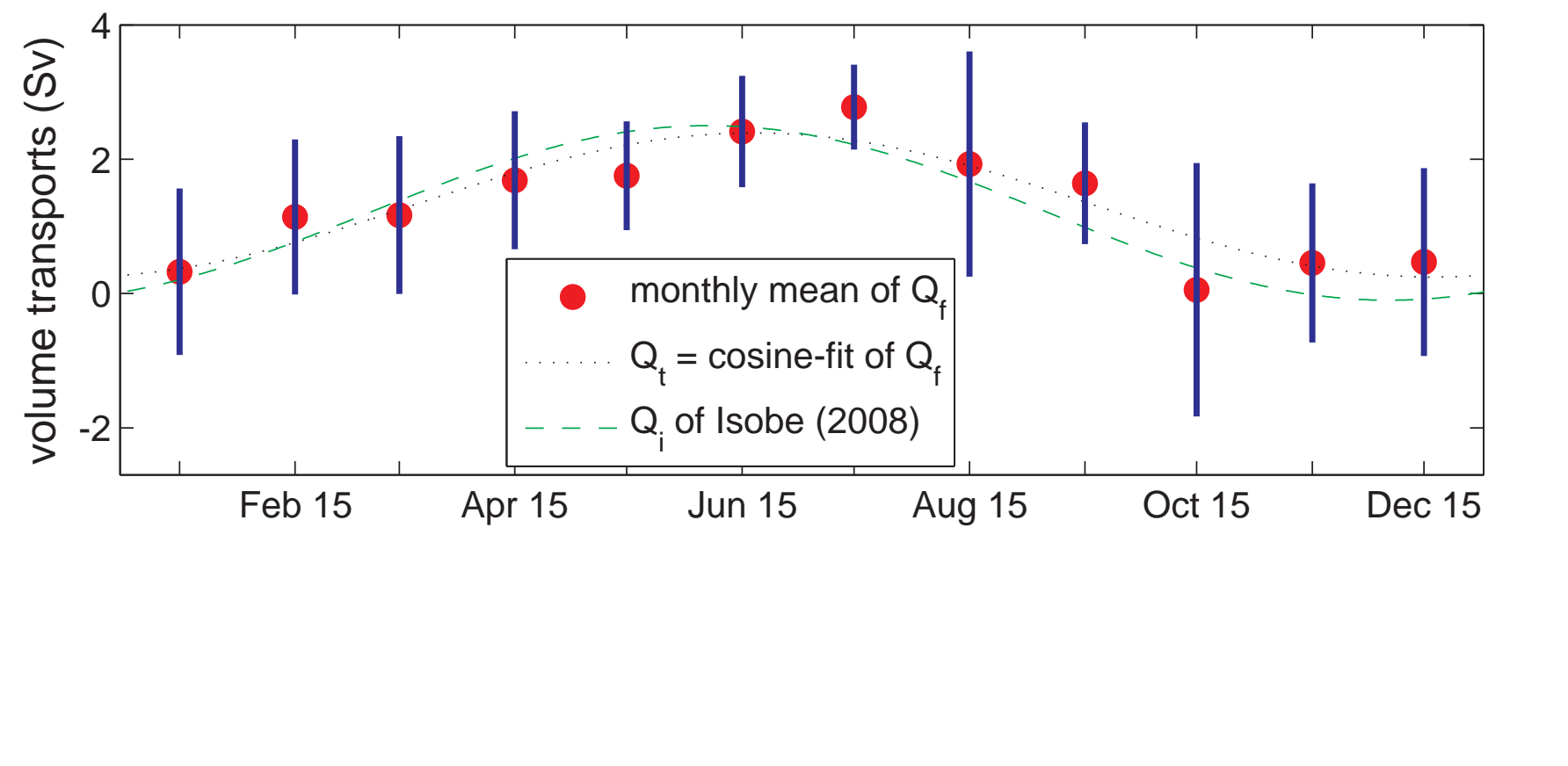


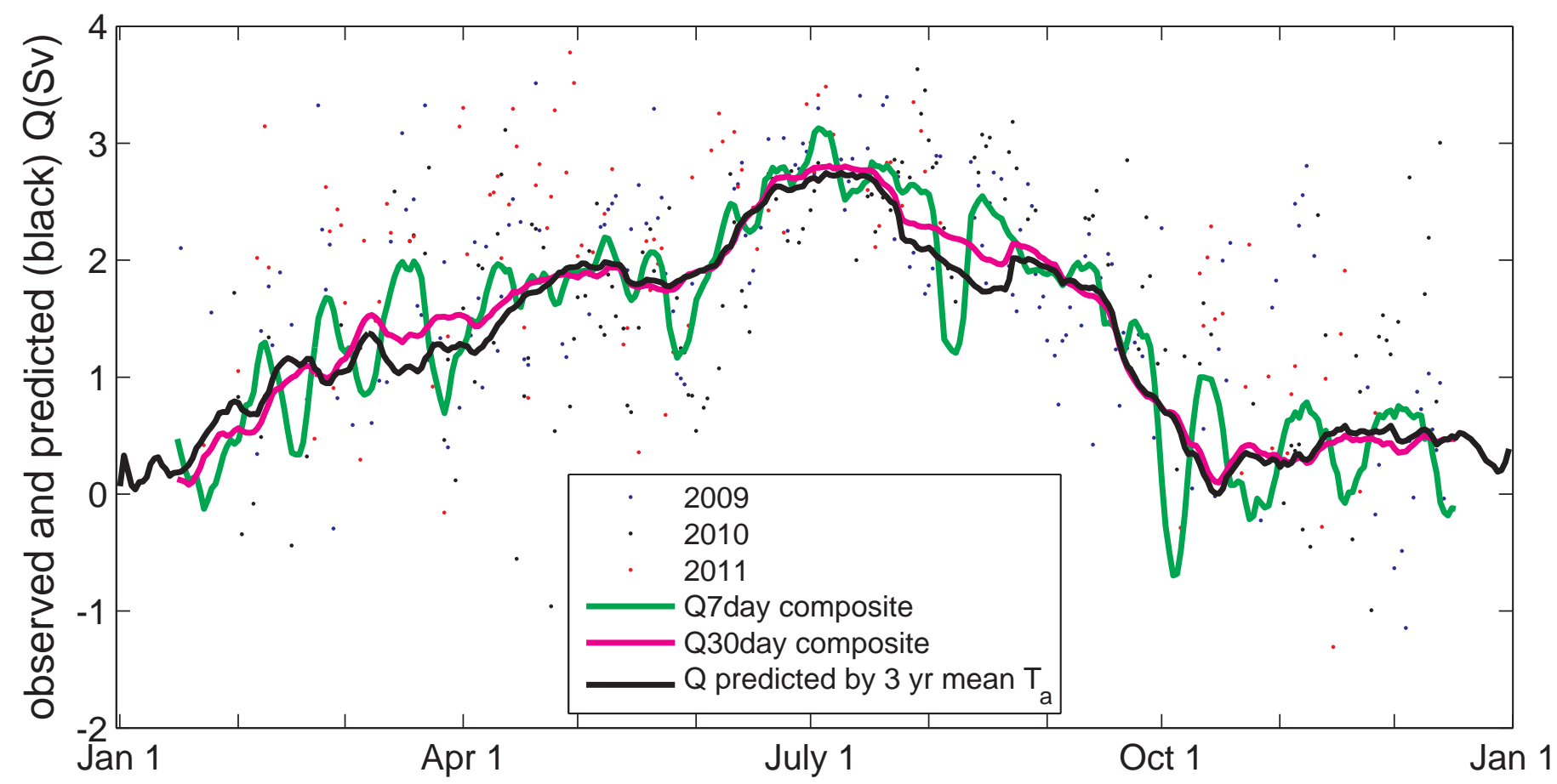




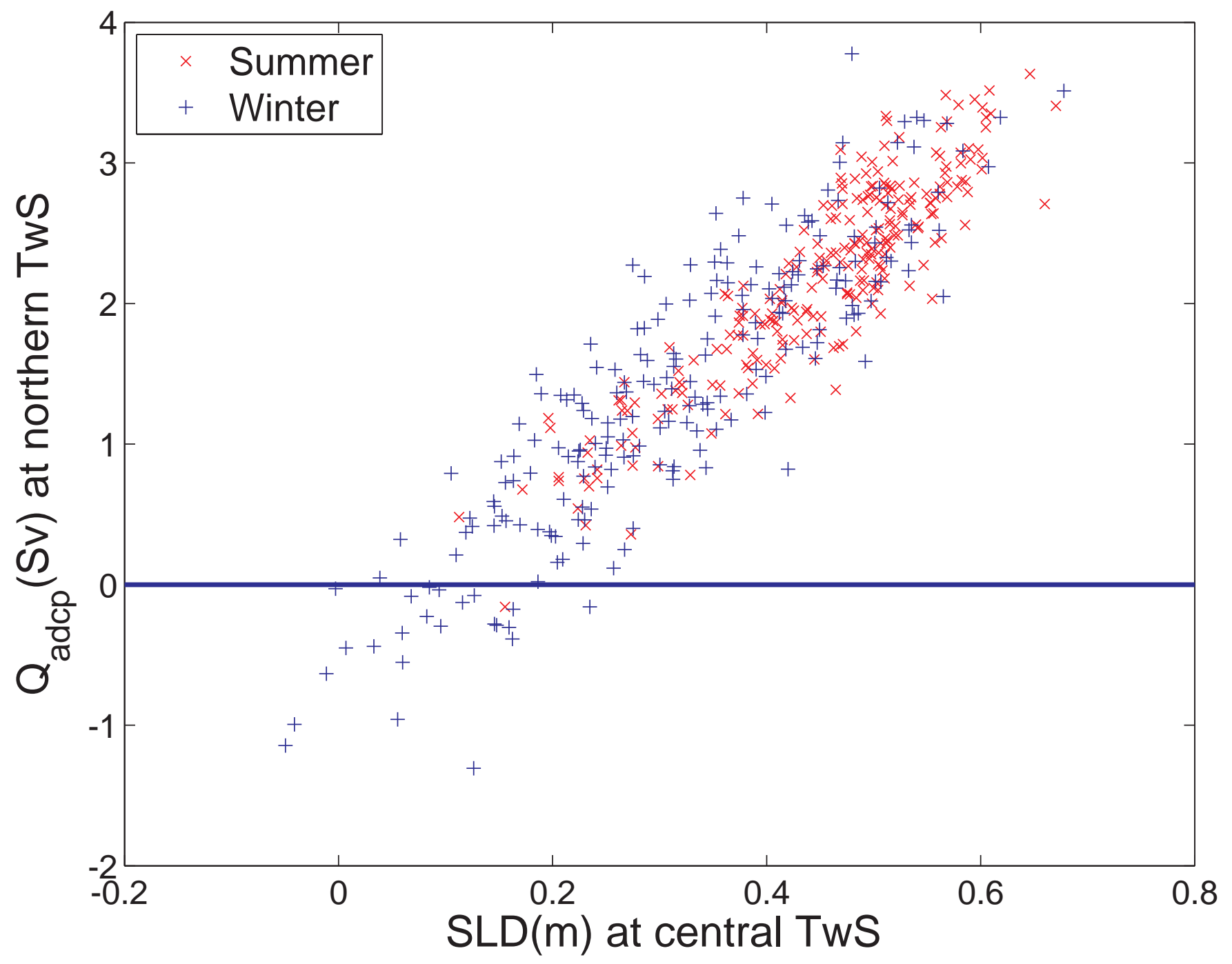


MAAD_PIC_4km.CR Porticulate Inorganic Carben 44m, 8-doy [mol $\left.\mathrm{m}^{\wedge}-3\right]$
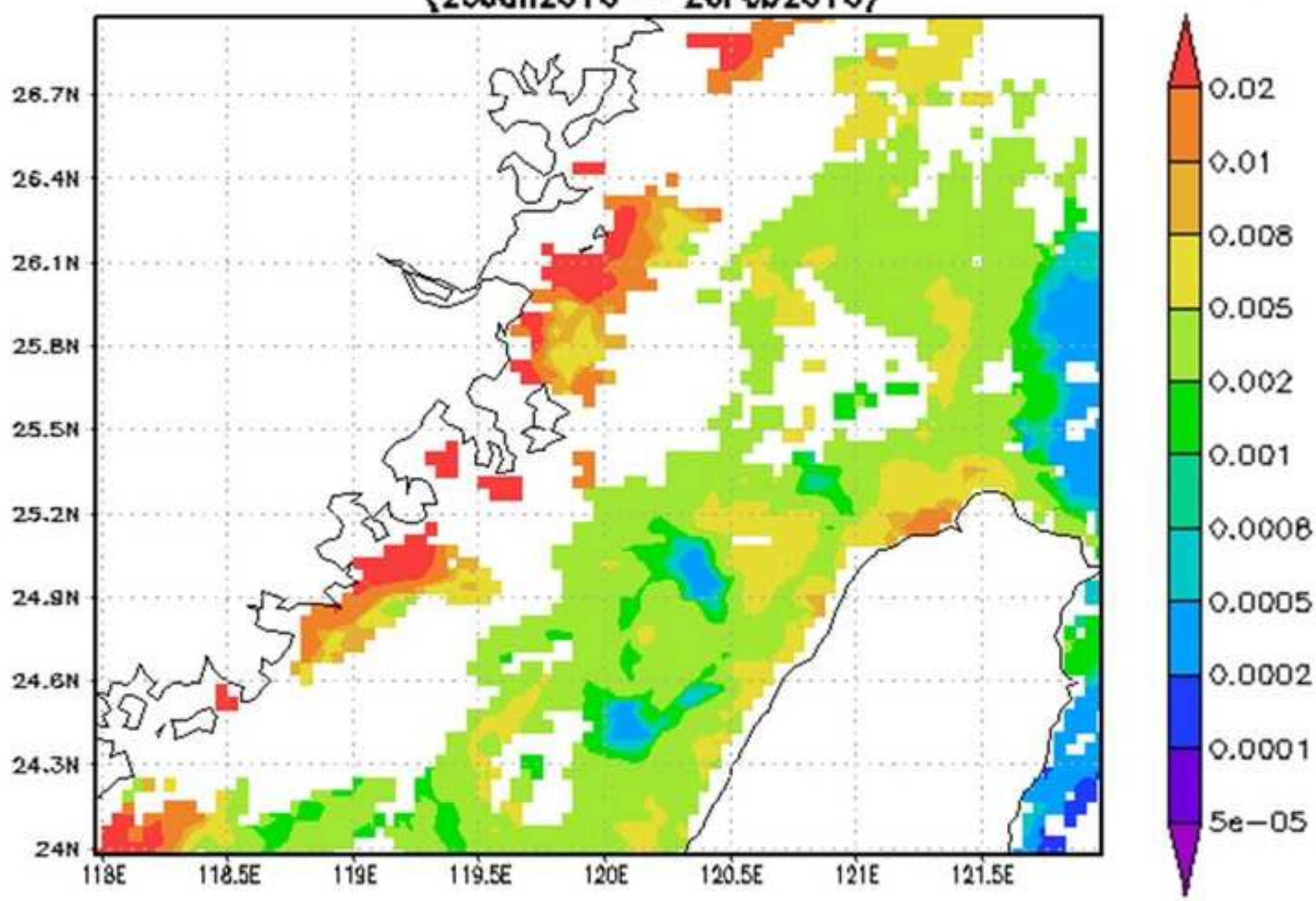
Table 1. Number of cruises in each month of 2009 to 2011.

\begin{tabular}{|l|c|c|c|}
\hline & 2009 & 2010 & 2011 \\
\hline Jan & 3 & 1 & 1 \\
\hline Feb & 13 & 9 & 11 \\
\hline Mar & 18 & 8 & 14 \\
\hline Apr & 19 & 20 & 19 \\
\hline May & 22 & 24 & 19 \\
\hline Jun & 16 & 19 & 14 \\
\hline Jul & 19 & 17 & 17 \\
\hline Aug & 22 & 18 & 3 \\
\hline Sep & 21 & 13 & 1 \\
\hline Oct & 12 & 8 & 14 \\
\hline Nov & 8 & 16 & 10 \\
\hline Dec & 14 & 6 & 0 \\
\hline
\end{tabular}


Table 2. Monthly mean values of along-strait wind stress $T_{a}$ and the various volume transport values, including $Q_{a d c p}{ }^{\mathrm{a}}, Q_{f}{ }^{\mathrm{b}}, Q_{\mathrm{fm}}{ }^{\mathrm{c}}$, and $Q_{i}^{\mathrm{d}}$.

\begin{tabular}{|c|c|c|c|c|c|c|c|c|c|c|c|c|}
\hline & \multirow{2}{*}{$\frac{T_{a}(\mathrm{~Pa})}{\text { mean }}$} & \multicolumn{5}{|c|}{$Q_{a d c p}(\mathrm{~Sv})$} & \multicolumn{3}{|c|}{$Q_{f}$} & \multicolumn{2}{|c|}{$Q_{f m}$} & \multirow[t]{2}{*}{$Q_{\mathrm{i}}$} \\
\hline & & 2009 & 2010 & 2011 & mean & std dev & 2009 & 2010 & 2011 & mean & std dev & \\
\hline Jan & -0.104 & 1.754 & 1.721 & 0.419 & 1.298 & 0.761 & 0.445 & 0.795 & -0.199 & 0.347 & 0.504 & 0.231 \\
\hline $\mathrm{Feb}$ & -0.052 & 1.456 & 0.446 & 1.911 & 1.271 & & & 1.049 & 1.144 & 1.147 & 0.100 & 0.773 \\
\hline Mar & -0.054 & 1.551 & 1.692 & 1.68 & 1.641 & 0.078 & & 1.382 & 1.141 & 1.187 & 0.176 & 1.427 \\
\hline Apr & -0.021 & 1.809 & 1.453 & 2.584 & 1.949 & 0.578 & 1.561 & 1.253 & 2.242 & 1.685 & 0.506 & 2.03 \\
\hline May & -0.014 & 2.023 & 1.602 & 1.795 & 1.807 & 0.211 & 1.978 & 1.671 & 1.596 & 1.749 & 0.202 & 2.409 \\
\hline Jun & 0.021 & 2.569 & 1.882 & 2.694 & 2.381 & & 2.526 & 1.912 & 2.759 & 2.399 & 0.437 & 2.465 \\
\hline Jul & 0.037 & 2.745 & 2.748 & 2.818 & 2.77 & & 2.689 & 2.823 & 2.764 & 2.758 & 0.067 & 2.178 \\
\hline Aug & -0.017 & 2.246 & 2.602 & 2.207 & 2.352 & 0.218 & 1.355 & 2.384 & 2.080 & 1.940 & 0.529 & 1.619 \\
\hline Sept & -0.02 & 1.357 & 1.916 & 0.78 & 1.351 & 0.568 & 1.431 & 2.104 & 1.293 & 1.609 & 0.434 & 0.954 \\
\hline Oct & -0.117 & 0.936 & 0.996 & 1.12 & 1.017 & 0.094 & 0.150 & -0.164 & 0.282 & 0.090 & 0.229 & 0.356 \\
\hline Nov & -0.085 & 1.646 & 0.636 & 0.569 & 0.95 & & 0.413 & 0.464 & 0.434 & 0.437 & 0.026 & -0.017 \\
\hline Dec & -0.089 & 0.551 & 1.98 & no data & 1.265 & 1.010 & 0.603 & 0.976 & -0.231 & 0.449 & 0.618 & -0.06 \\
\hline mean & -0.043 & 1.72 & 1.639 & 1.689 & 1.671 & 0.436 & 1.286 & 1.387 & 1.275 & 1.316 & 0.436 & 1.2 \\
\hline std dev & 0.049 & 0.630 & 0.694 & 0.862 & 0.587 & 0.316 & 0.819 & 0.844 & 1.056 & 0.856 & 0.207 & 0.949 \\
\hline
\end{tabular}

${ }^{\mathrm{a}} Q_{a d c p}:$ the observed volume transport,

${ }^{\mathrm{b}} Q_{f}$ : the volume transport with gaps filled by $Q_{e}$,

${ }^{\mathrm{c}} Q_{f m}$ : the three-year composite of the monthly means of $Q_{f}$,

${ }^{\mathrm{d}} Q_{i}$ : the analytic approximation of volume transport by Isobe (2008). 